\title{
Anaclitic-sociotropic and introjective-autonomic personality dimensions and depressive symptoms: a systematic review
}

\author{
Angelica Marfoli, Federica Viglia, Micaela Di Consiglio, Sheila Merola, Stefano Sdoia and
}

Alessandro Couyoumdjian *i()

\begin{abstract}
Sociotropy (anaclitic) and autonomy (introjective) are conceptualised as two personality dimensions that confer vulnerability to depression. According to Blatt and Beck's theories, sociotropic individuals exhibit distinctive patterns of symptoms such as prominent anxiety, depressed mood, helplessness, crying and somatic concerns, while self-critical ones seem to exhibit a pattern of symptoms including prominent guilt, hopelessness, feelings of failure and worthlessness and other cognitive symptoms.

This systematic review was performed with the aim of investigating whether and to what extent psychological dimensions of anaclitic-sociotropic and introjective-autonomy are related to a specific core of depressive symptoms. The search was conducted in three databases (PubMed, PsycINFO and Scopus) and 27 articles were selected.

Results showed a weak association between somatic symptoms and dependent personality traits, while the relationship between self-criticism and cognitive symptomatology was significantly higher. These findings are discussed in the context of future research, necessary to corroborate the existence of a form of depression characterised by somatic features usually ignored by diagnostic criteria, essential to direct psychological treatments to these depressive personality differences.
\end{abstract}

Keywords: Sociotropic personality, Autonomic personality, Psychological dimensions, Depression, Depressive symptoms, Complicated grief

\section{Introduction}

Depression is one of the most common and invalidating mental disorders in current society [45] and it can be very heterogeneous due to several possible combinations of symptoms [39]. Zimmermann and colleagues (2015 identified 227 possible depressive patterns, suggesting that depressed people may have clinical conditions

*Correspondence: alessandro.couyoumdjian@uniroma1.it Dipartimento di Psicologia, Sapienza Università di Roma, Via dei Marsi 78 , 00185 Roma, Italy that differ drastically. Furthermore, the comorbidity of depression with other psychological or medical disorders, such as anxiety disorders or post-traumatic stress disorder (PTSD, [2, 20, 46], or even other chronic illnesses [53], shows how depressive symptomatology can vary. Also, specific behaviours that are often considered to be the clinical manifestation of major depressive disorder, particularly suicidality and suicidal ideation, seem to not be typical of depression, but can emerge from human sadness. This lack of information can also affect therapeutic efficiency [66]. The tendency to ignore original author(s) and the source, provide a link to the Creative Commons licence, and indicate if changes were made. The images or other third party material in this article are included in the article's Creative Commons licence, unless indicated otherwise in a credit line to the material. If material is not included in the article's Creative Commons licence and your intended use is not permitted by statutory regulation or exceeds the permitted use, you will need to obtain permission directly from the copyright holder. To view a copy of this licence, visit http://creativecommons.org/licenses/by/4.0/. The Creative Commons Public Domain Dedication waiver (http://creativeco mmons.org/publicdomain/zero/1.0/) applies to the data made available in this article, unless otherwise stated in a credit line to the data. 
symptomatic variations of Major Depressive Disorder could explain the lack of progress about the validation of under-diagnosis and the identification of differential treatments that are effective and adequate. In line with this hypothesis, Sidney Blatt [12]—from a psychoanalytic perspective-and Aaron T. Beck [8] — from a cognitive point of view-assumed that different traumatic experiences in childhood can lead to two different personality dimensions that are prone to depression in adulthood. The personality dimensions described by Blatt-anaclitic and introjective-and those described by Beck-sociotropic and autonomic - can be considered as equivalents: anaclitic and sociotropic are overlapping concepts, as are introjective and autonomic. They are also referred to as dependency and self-criticism, respectively. The anacliticsociotropic dimension refers to a dependent personality style that is sensitive to the disruption of interpersonal relationships and is characterised by a strong need to be loved and taken care of, together with exaggerated fears of loss and abandonment, and a tendency to seek help and support from the others, especially when faced with stress. It includes feelings of loneliness, weakness and helplessness, and it is more frequent in women. An introjective-autonomic personality instead implies a strong emphasis on control, self-definition, autonomy, and concerns about personal goals and high standards. The main feelings associated with this are self-devaluation, low self-worth, self-criticism, sense of inferiority and guilt, and it has to do with a narcissistic vision of oneself [12, 51]. Several studies [19, 30, 47, 69] in recent decades have focused on these distinctive patterns of symptoms shown by these different personality configurations according to the Symptoms Specificity Hypothesis [13], the aim of which was to clarify the specific relationships between a pre-existing depressive personality and specific depression symptoms. According to this hypothesis, sociotropic individuals in particular should show distinctive patterns of symptoms such as prominent anxiety, depressed mood, helplessness, crying and somatic concerns. Selfcritical individuals, on the other hand, are more prone to developing a pattern of symptoms that includes prominent guilt, hopelessness, feelings of failure and worthlessness, suicidality, and other cognitive symptoms.

The general purpose of this systematic review is to provide robust data concerning the relationship between anaclitic-sociotropic and introjective-autonomy dimensions and specific depressive symptoms among depressed patients. Thus, different typical depressive symptoms such as anhedonia, shame, uncontrolled crying, suicidality, anger, insomnia, rumination, and self-criticism are taken into consideration to evaluate if they are more often frequent in people showing an anaclitic-sociotropic personality or an introjective-autonomic one.
The ultimate goal of this work is to demonstrate how often diagnostic criteria for depression, for example Diagnostic and Statistical Manual of Mental Disorders diagnostic criteria [2] tend to mainly highlight only a cognitive symptom pattern, which is typical of the introjective-autonomic configuration of depressive personality. However, little attention is paid to other depressive forms distinguished by a more somatic symptomatology, which is recurrent in anaclitic-sociotropic personalities. This manifestation also appears to be strongly related to the emotional experiences of people who suffer from Complicated Grief Disorder.

For this reason, complicated grief symptomatology will be considered in order to underline its correlation to anaclitic-sociotropic depression symptoms and to show that there are many different forms of major depressive disorder that should not be ignored.

Considering these personality differences while orienting depression treatment is another important purpose of this study.

\section{Method}

A systematic review was performed in compliance with the PRISMA guidelines for systematic reviews and metaanalyses (see Fig. 1) [54].

\section{Information sources and database search}

In order to systematically collect empirical studies on the relation between personality dimensions (anaclitic-sociotropic trait versus introjective-autonomic trait) and different depressive manifestations, several keywords were used to search for appropriate publications in three electronic databases: PubMed, Scopus, PsycINFO.

Two separate reviewers conducted the search in each database for the following two groups of keywords: (a) terms related to personality traits: "anaclitic" and "introjective" personality OR trait", "dependency" and "self-critical" personality OR trait", "sociotropic" and "autonomic" personality OR trait", "Depressive Experiences Questionnaire" (DEQ), "Sociotropy and Autonomy Scale" (SAS); (b) terms related to pathological outcomes: "depressive symptom"," "depression", "complicated grief", "bereavement".

Key words should be part of the title or the abstract of the literature.

\section{Literature search strategy and eligibility criteria}

All duplicates and non-relevant records focusing on title and abstract were removed and the most relevant full texts were analysed and included according to eligibility criteria. The inclusion criteria are the following: (1) only articles published in English in peerreviewed journals; (2) studies had to consider the 


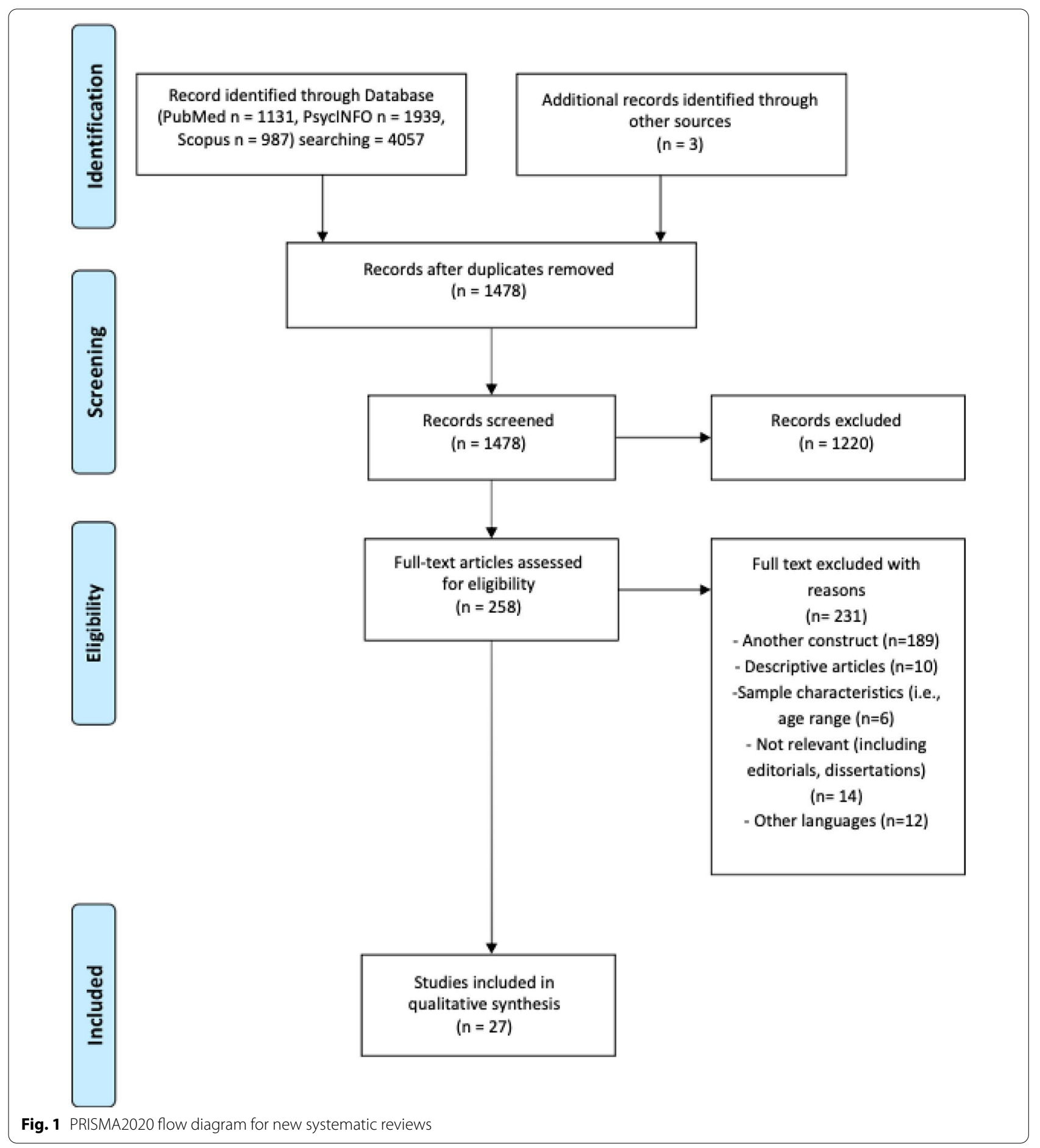

relationship between anaclitic-sociotropic or introjective-autonomic personality and depressive symptoms; (3) depressive symptoms had to be assessed using a validated method; all tests measuring self-critical and dependent personality traits and depressive symptoms were selected; (4) the population group of interest were adults (over 18 years of age). Exclusion criteria are as follow: (1) the presence of comorbidities with other psychiatric disorders; (2) children's samples.

Additionally, citations in retrieved articles were screened to identify extra relevant publications. All 
worthwhile articles were selected and screened based on the aforementioned eligibility criteria.

\section{Data extraction}

The analysis was conducted by two separate reviewers, who applied the eligibility criteria in each database. The same two authors carried out the selection of the studies, separately and together. In case of disagreement on the inclusion of a study, the two authors discussed their point of view until a consensus was reached. Where necessary, a third reviewer was involved to reach a consensus.

\section{Assessing the quality of selected studies}

The evaluation of the risk of bias was conducted by a quality index derived from the Qualsyst' Tool [48]. The quality assessment of the studies appears from moderate to strong (see Appendix A).

\section{Results}

For the purpose of this systematic review, 27 studies examining the relationship between personality and depression symptoms in adults were identified, fulfilling the inclusion and exclusion criteria. Tables 1, 2 and 3 summarise data about samples, assessment of personality and depression symptoms, and the main results of each study per cluster of symptoms (somatic and cognitive symptoms, other symptoms and complicated grief, respectively). Figure 2 provides an overview of the tests that each study utilised to assess personality (Fig. 2, 2.2) and depression symptoms (Fig. 2, 2.1).

In the following paragraphs, all included articles have been described according to the cluster of symptoms.

\section{Somatic and cognitive symptoms}

Seven studies [30, 47, 51, 59, 69, 71, 79] were identified examining the relationship between personality and somatic symptoms in adults (age range 18-70 years).

The main result is a significant positive association between dependent personality and indecisiveness $[\beta=0.229 ; \quad \mathrm{F}(1,25)=8.811 ; \quad p=0.003], \quad$ worthlessness $[\beta=0.251 ; \mathrm{F}(1,25)=12.280 ; p=0.001]$ [30], and guilty feelings $(\beta=0.383, \mathrm{t}=2.898, p=0.006)$ [79]. The selfcritical personality also showed significant positive associations with Beck Depression Inventory-II [9] symptoms: pessimism $[\beta=0.215 ; \mathrm{F}(1,25)=7.551 ; p=0.007]$ [30], $(\beta=0.379, \mathrm{t}=2.869, p=0.006)$ [79], past failure $[\beta=0.324 ; \mathrm{F}(1,25)=19.123 ; p=0.000][30], \quad(\beta=0.436$, $t=3.391, \quad p=0.001)$ [79], guilty feelings $[\beta=0.356$; $\mathrm{F}(1,25)=23.325 ; p=0.000] \quad[30], \quad(\beta=0.406, t=3.112$, $p=0.003)$ [79], self-dislike $[\beta=0.390 ; \mathrm{F}(1,25)=29.484$; $p=0.000][30],(\beta=0.392, t=2.987, p=0.004)$ [79], selfcriticalness $[\beta=0.391 ; \mathrm{F}(1,25)=28.675 ; p=0.000]$ [30], $(\beta=0.437, t=3.400, p=0.001)$ [79], crying $[\beta=0.240$;
$\mathrm{F}(1,25)=9.772 ; p=0.002][30]$, indecisiveness $[\beta=0.234$; $\mathrm{F}(1,25)=9.561 ; \quad p=0.002] \quad[30], \quad(\beta=0.306, t=2.248$, $p=0.029)$ [79], worthlessness $[\beta=0.396 ; \mathrm{F}(1,25)=31.599$; $p=0.000$ ] [30], punishment feelings $(\beta=0.341, \mathrm{t}=2.540$, $p=0.014)$ [79], loss of interest $(\beta=0.328, t=2.430$, $p=0.019)$ [79], change in appetite $(\beta=0.363, t=2.723$, $p=0.009)$ [79], difficulty concentrating $(\beta=0.299$, $t=2.194, \quad p=0.033)$ [79], and tiredness or fatigue $(\beta=0,321, t=2.375, p=0.021)$ [79].

Results also show a significant relationship between Sociotropy and mood-variability, reactivity and loneliness, as well as Autonomy and loss of interest or pleasure, loss of interest in people, self-blame, irritability, and concern about inability to function [69], similar to Klein and colleagues' study [47] reporting higher levels of self-criticism being associated with the presence of loss of interest (overall Rao's $V=11.17$, change in $V=9.50, p=0.002$ ), and irritability (overall Rao's $V=6.17$ change in $V=6.07$, $p=0.01$ ). Furthermore, in the same study, higher levels of dependency were significantly associated with the presence of only one symptom, such as crying or tearfulness (overall Rao's $V=22.69$, change in $K=11.78, p<0.001$ ). [47].

Considering a theoretical sociotropic and autonomous symptoms composite as the sum of standardised scores on Beck Depression Inventory (BDI, [6] items, Hamilton Rating Scale for Depression (HRSD, [40] items and the Symptom Checklist-90 (SCL-90; [3] items, Robins and colleagues [71] report a stronger correlation between autonomy and autonomous symptoms (BDI itemshopelessness, guilt, self-blame, feeling like a failure, punishment, irritability, loss of satisfaction, disappointment in self and loss of functioning; HRSD items-feelings of guilt, difficulty working and social withdrawal; SCL-90 items-self-blame, hopelessness, loss of interest, worthlessness and feeling critical of others) than with theoretically sociotropic symptoms (BDI items-sad feelings, crying, decision-making difficulty, negative body image and somatization; HRSD items-depressed mood, general somatic problems, somatic anxiety, and positive psychic anxiety; SCL-90 items - all anxiety and phobic anxiety) $(z=3.03, p<0.01)$. Instead, sociotropy does not show the predicted pattern [71].

Luyten et al. [51] also considered dependent (D-COM) and self-critical (SC-COM) symptom composites. For D-COM, the authors identified symptoms such as: sad mood, feeling ugly, crying spells, worrying about physical problems (BDI), constipation, tachycardia, crying spells (ZUNG Self-Rating Depression Scale; ZUNG-SDS, 1965), crying easily, feeling lonely, worrying too much about things and feeling hurt and rejected (SCL-90). For SC-COM they considered the items: pessimism, guilty feeling, self-blame, irritability, indecisiveness, feelings of 


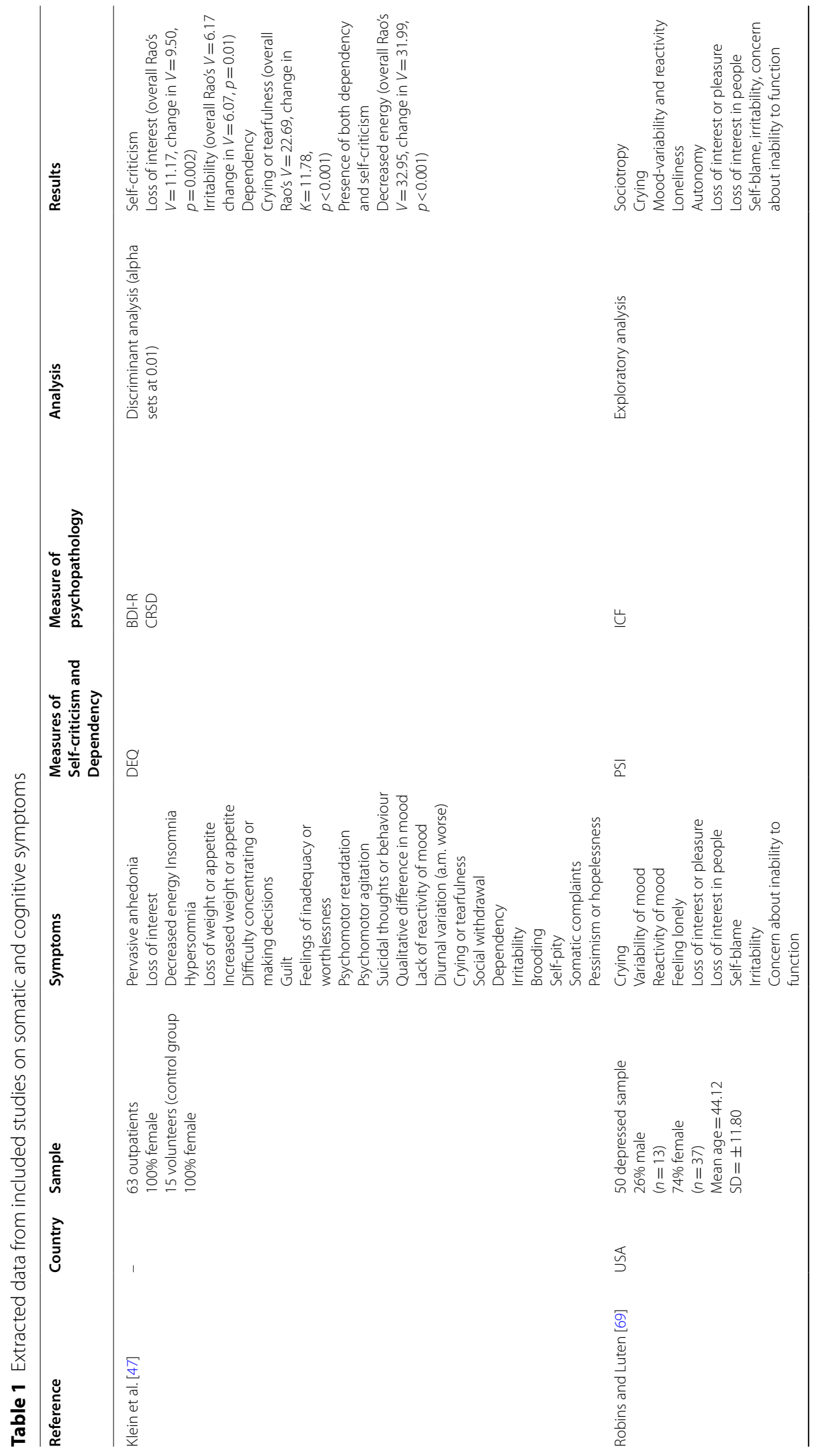




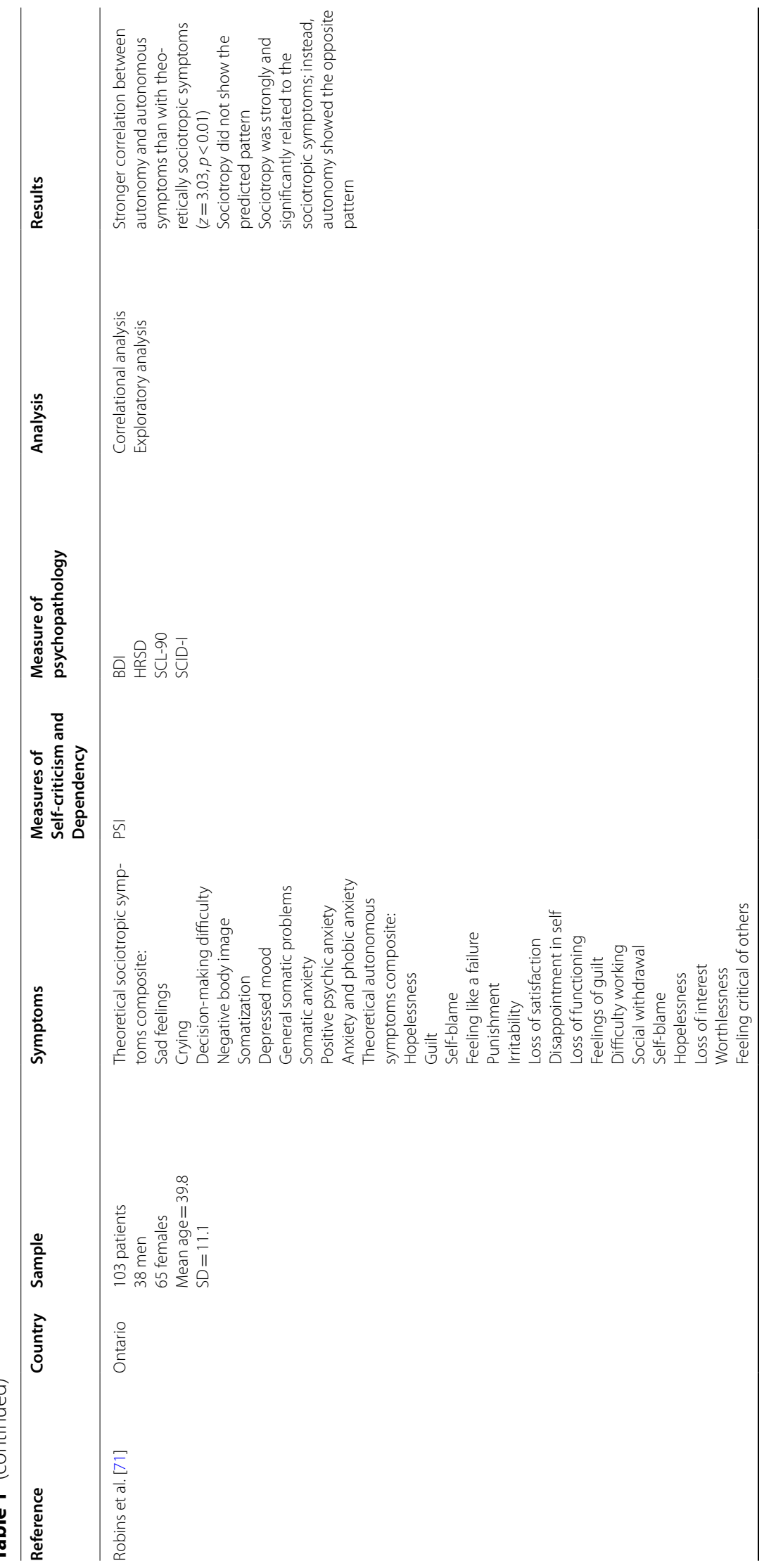




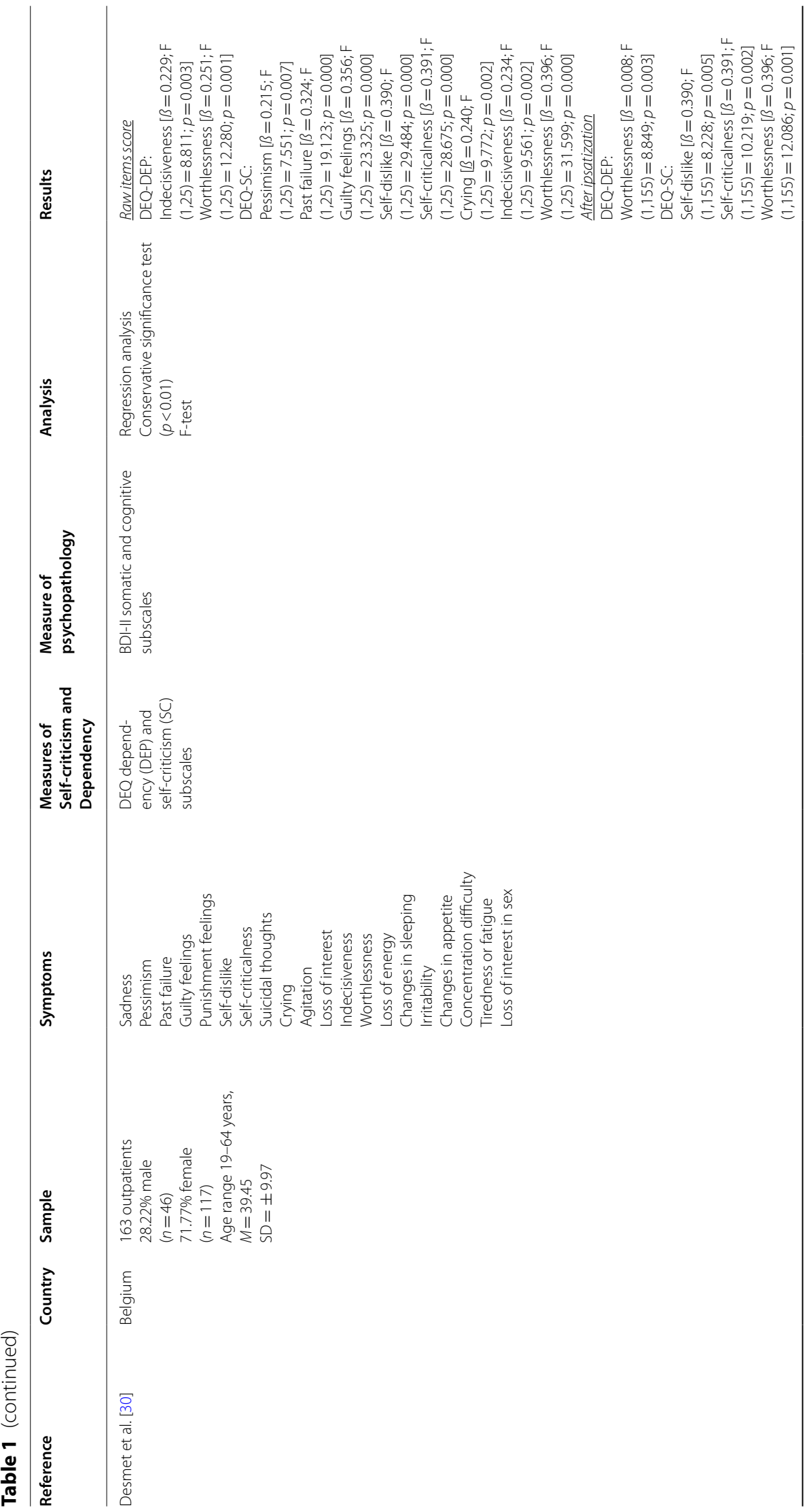




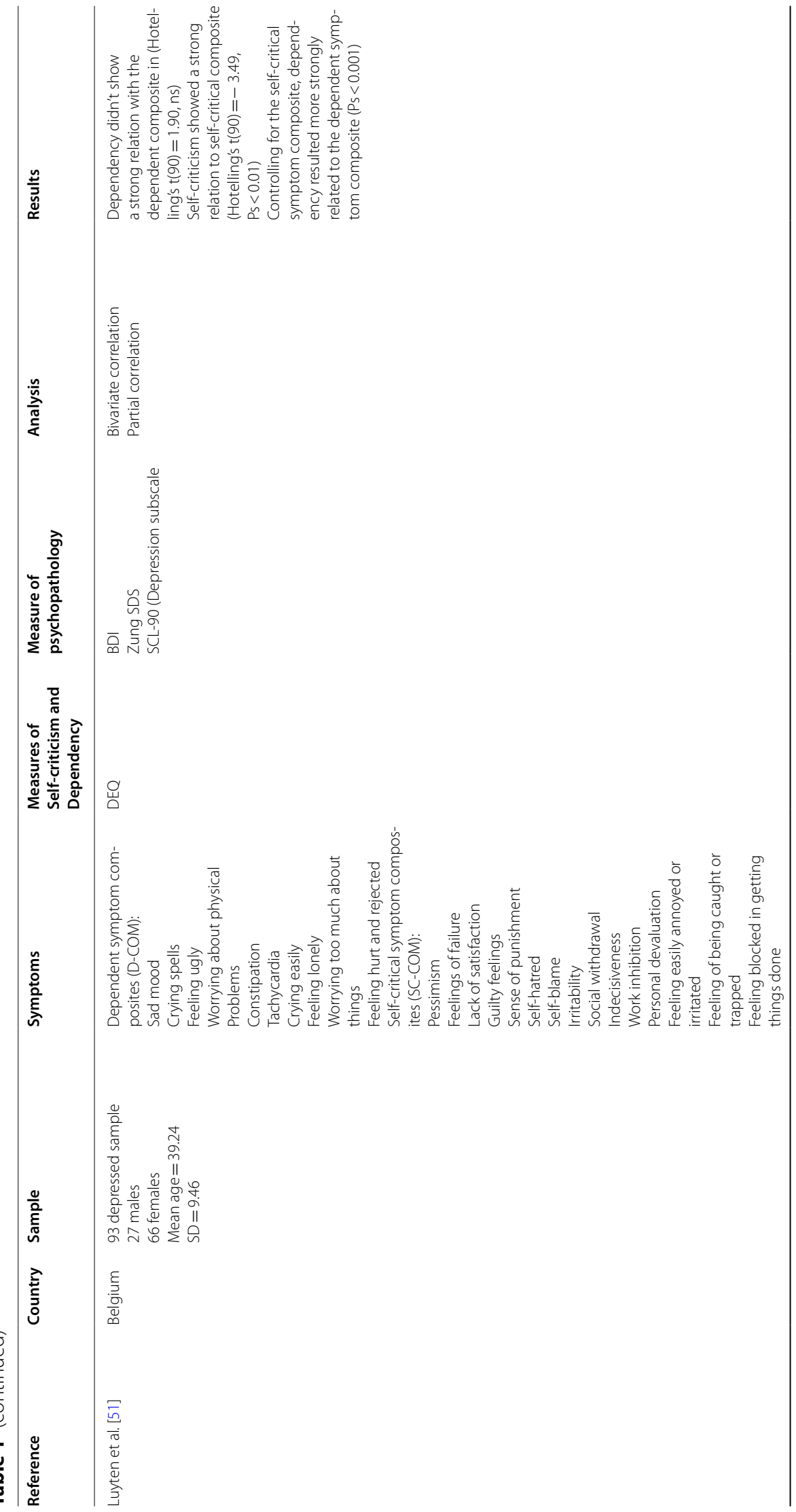




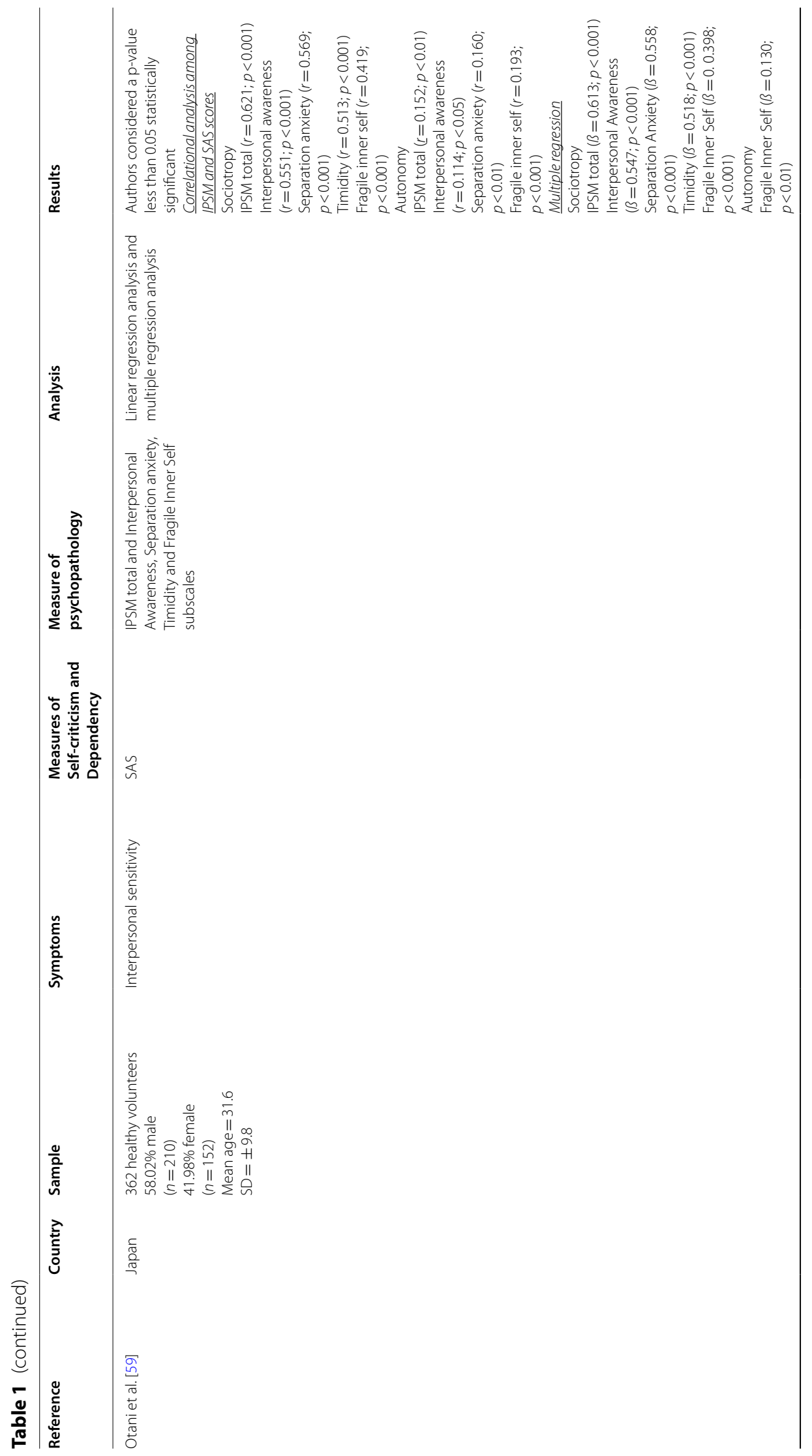




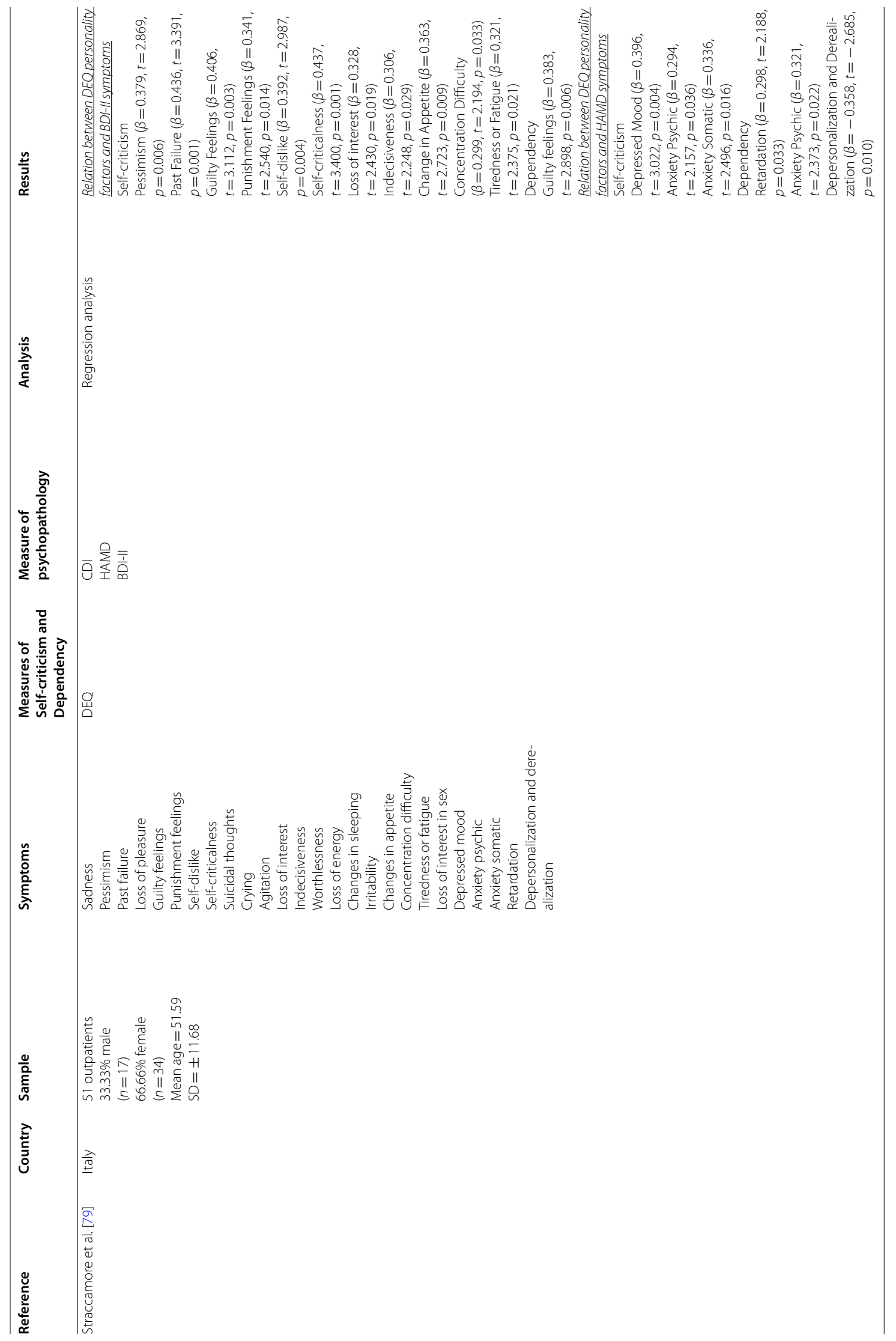




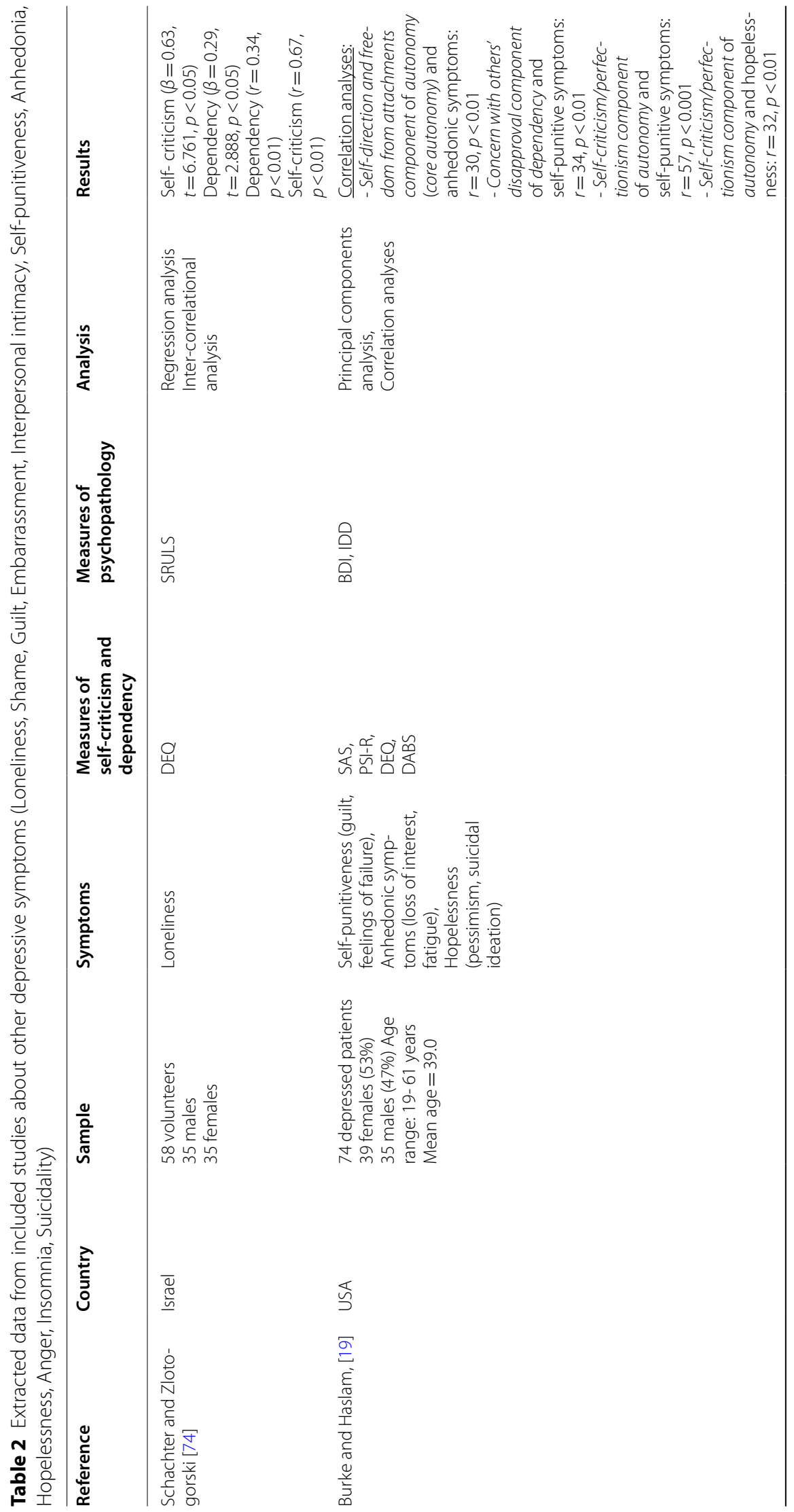




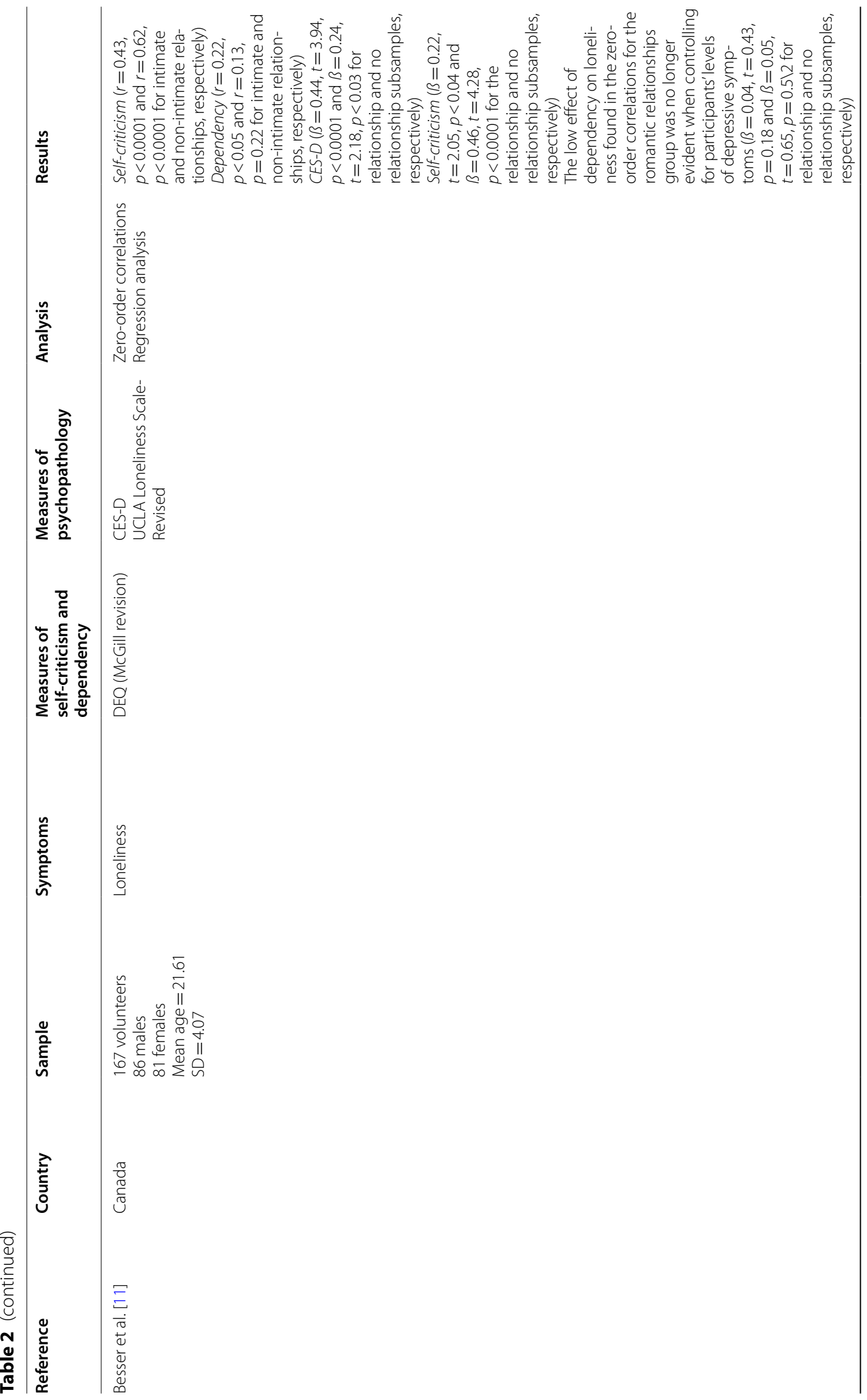




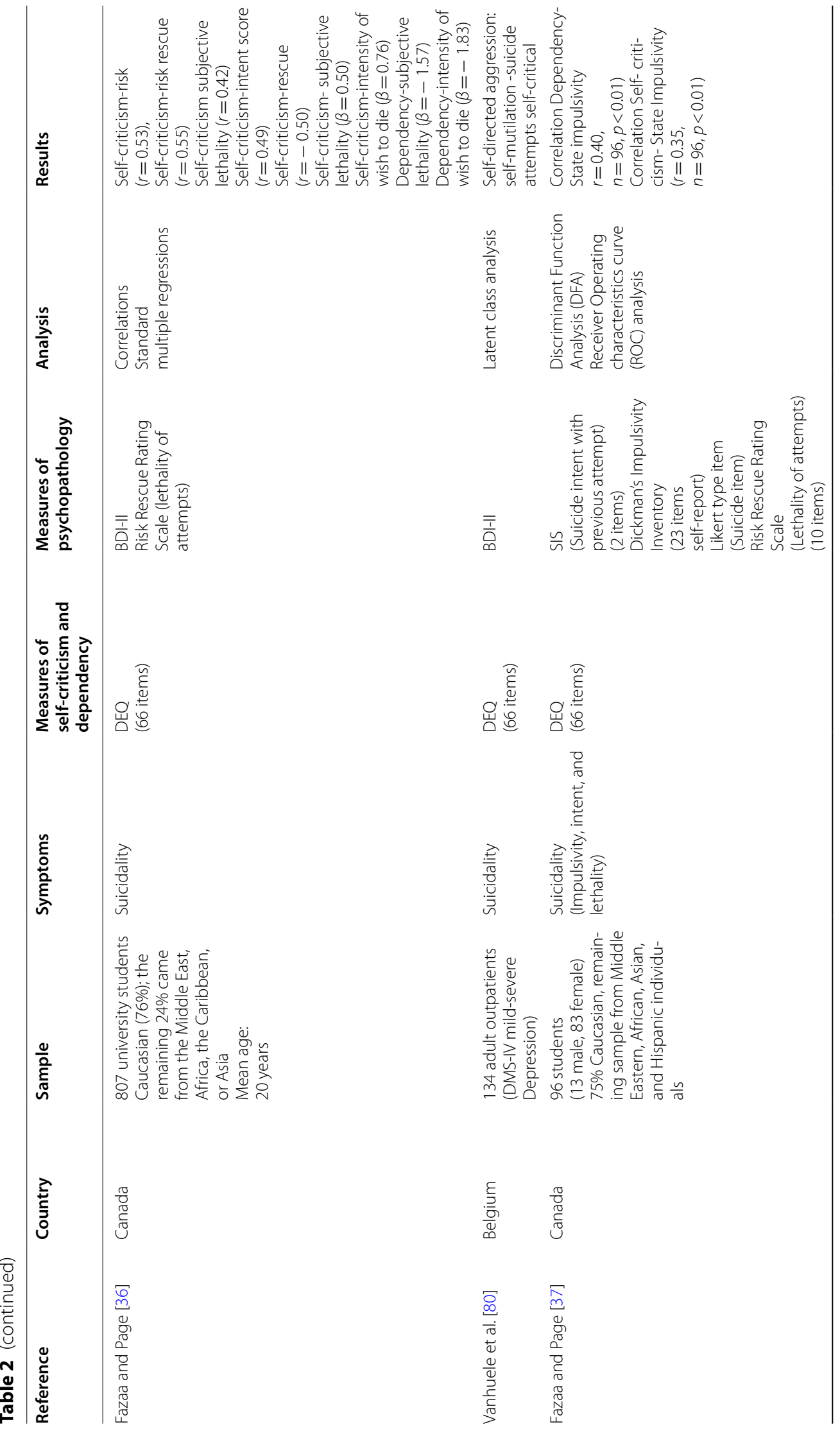




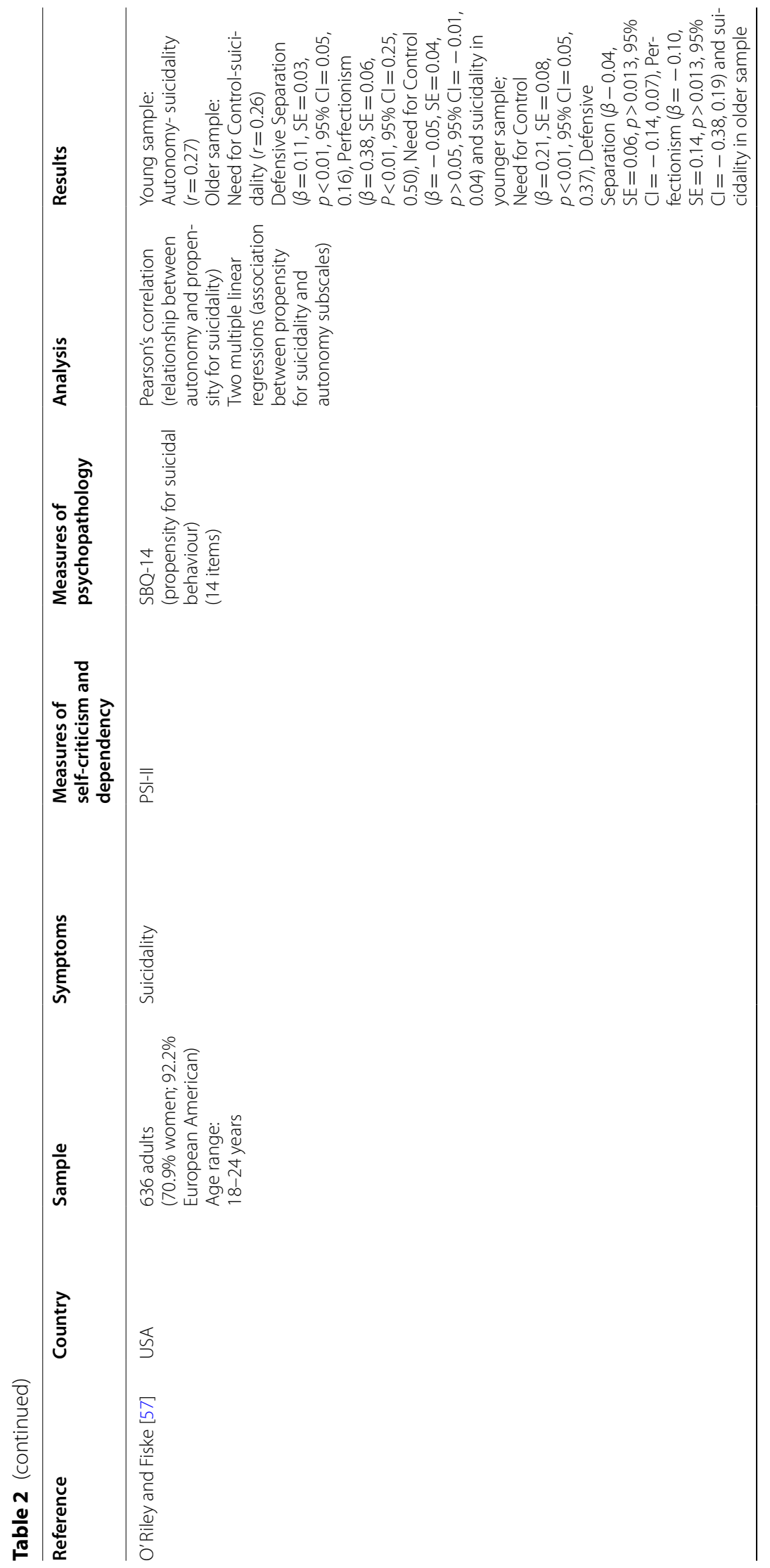




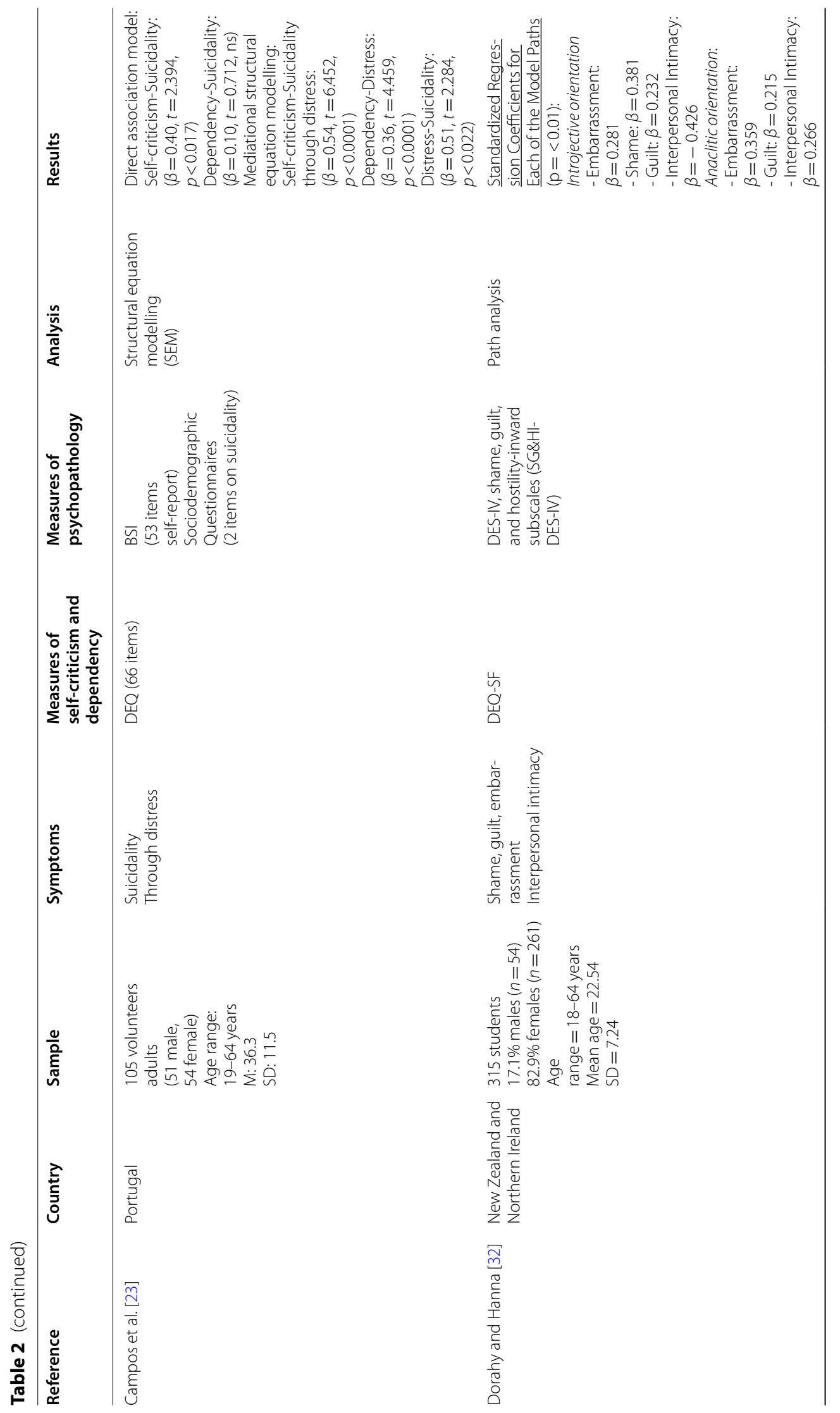




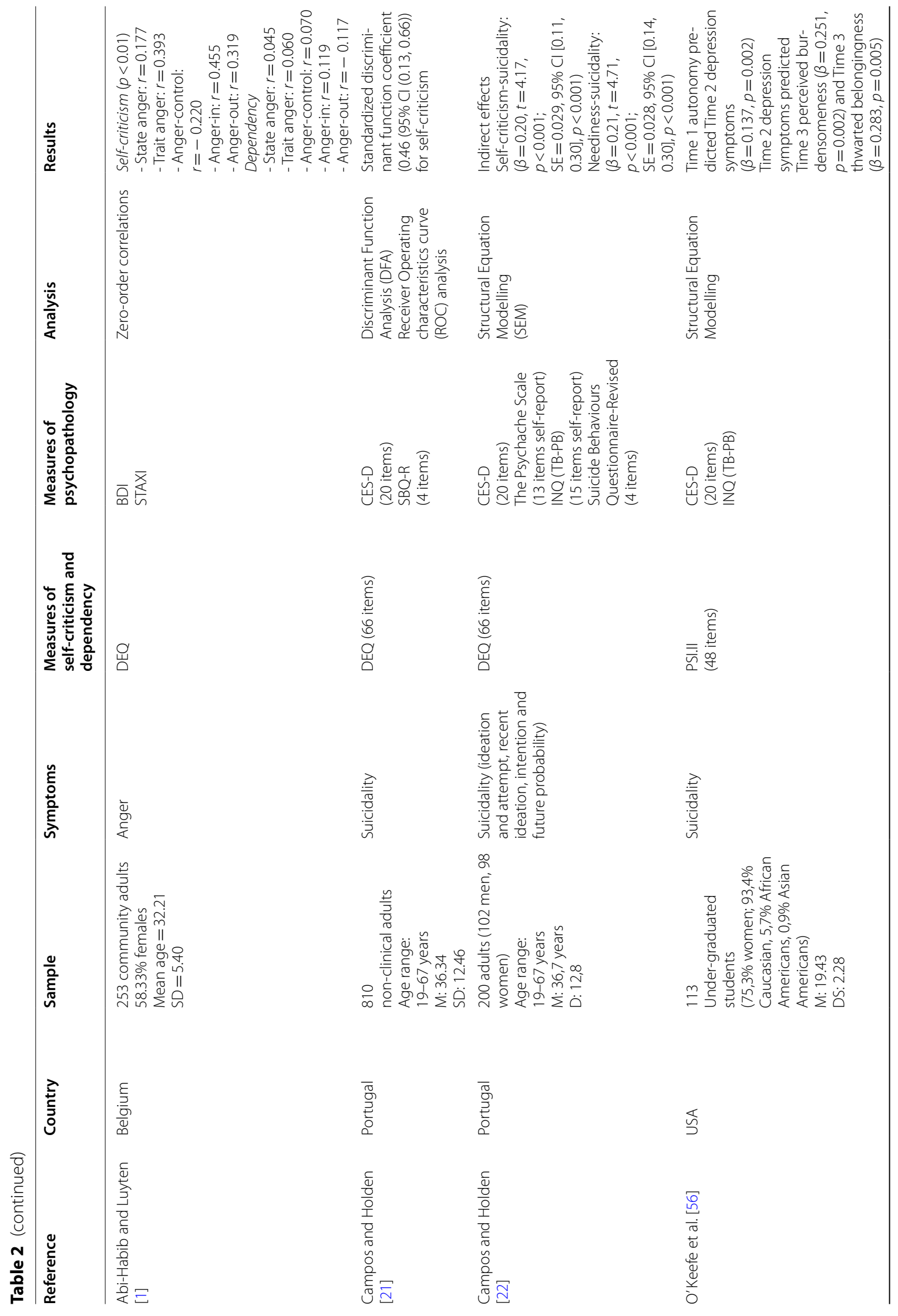




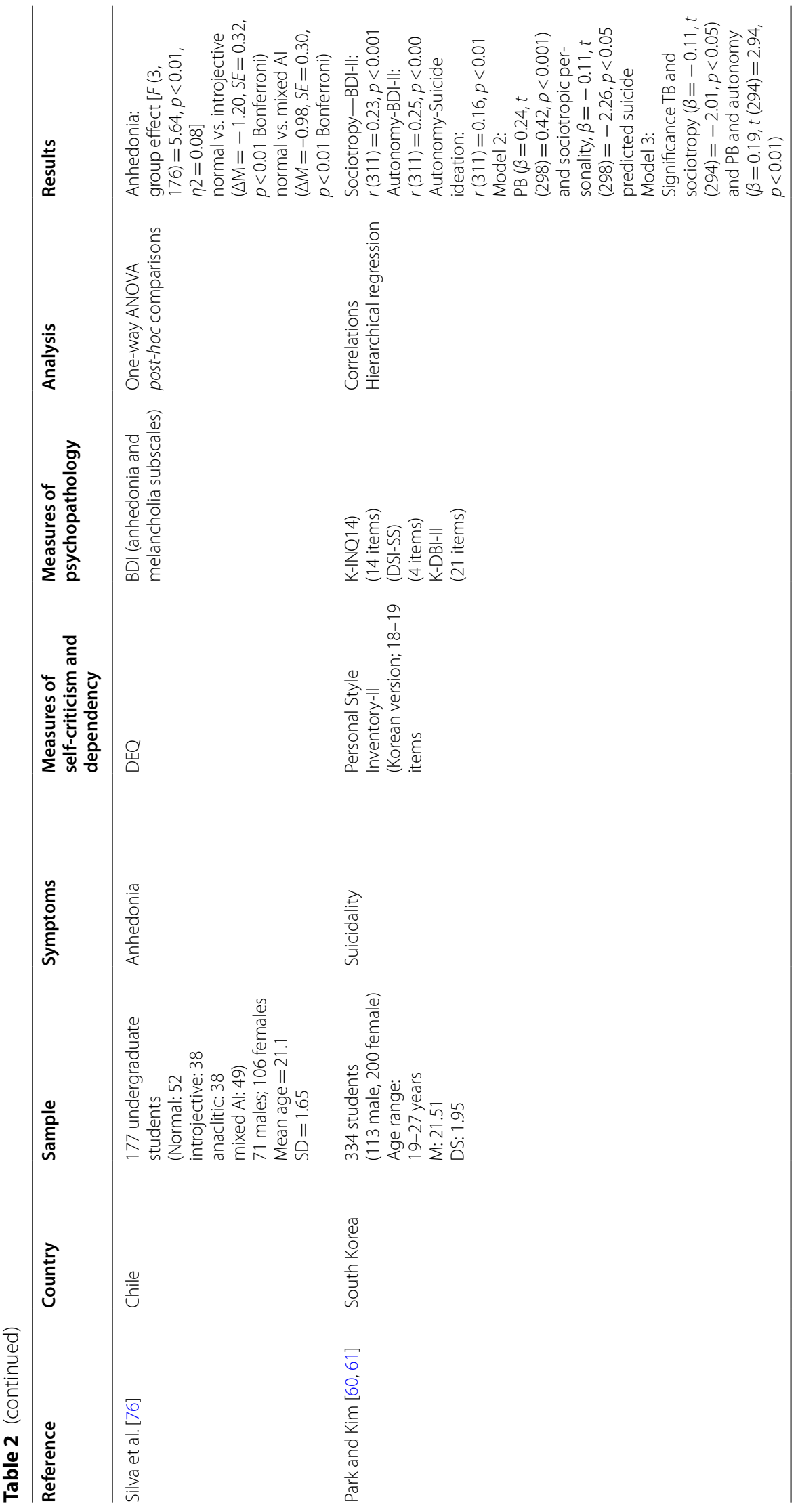




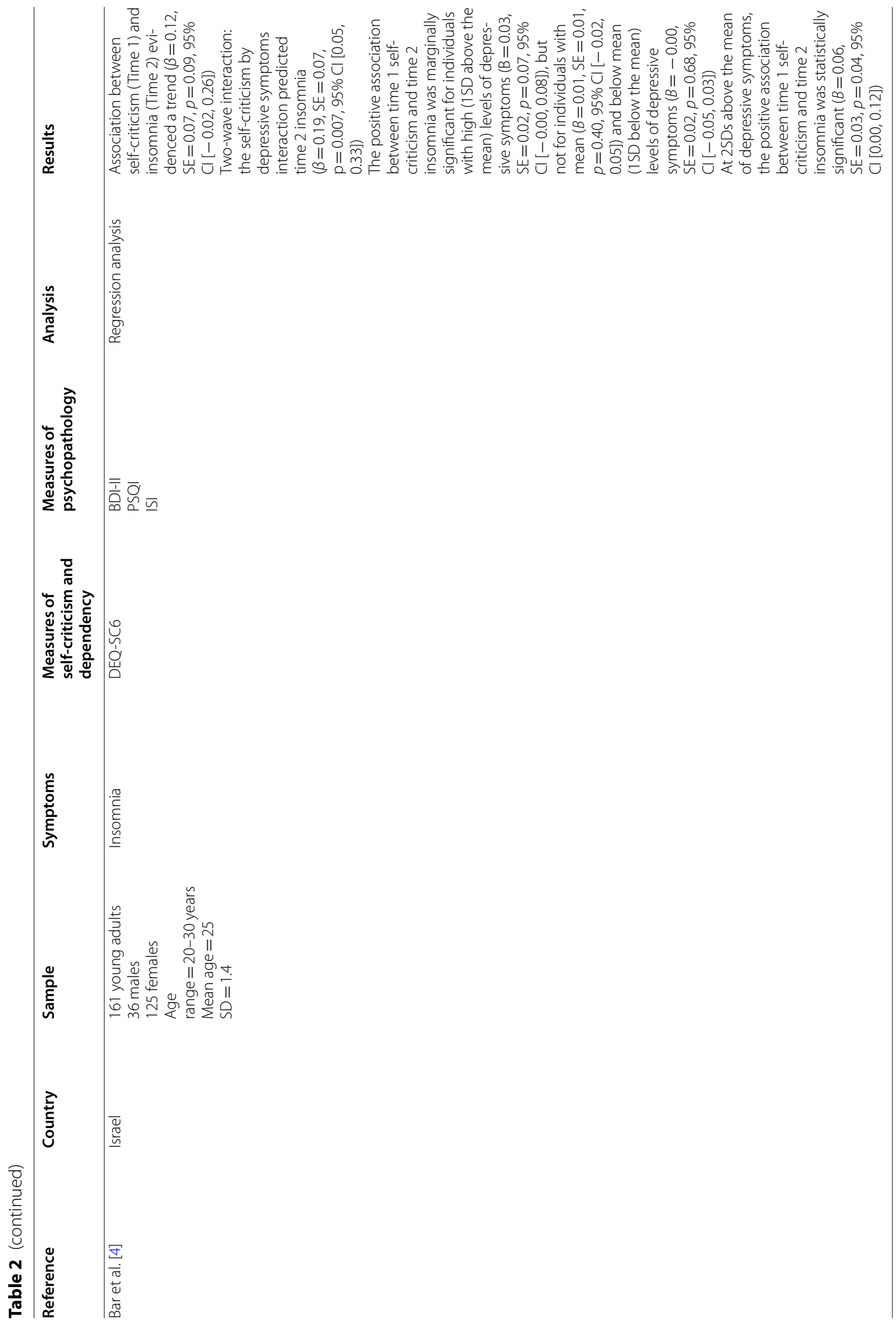




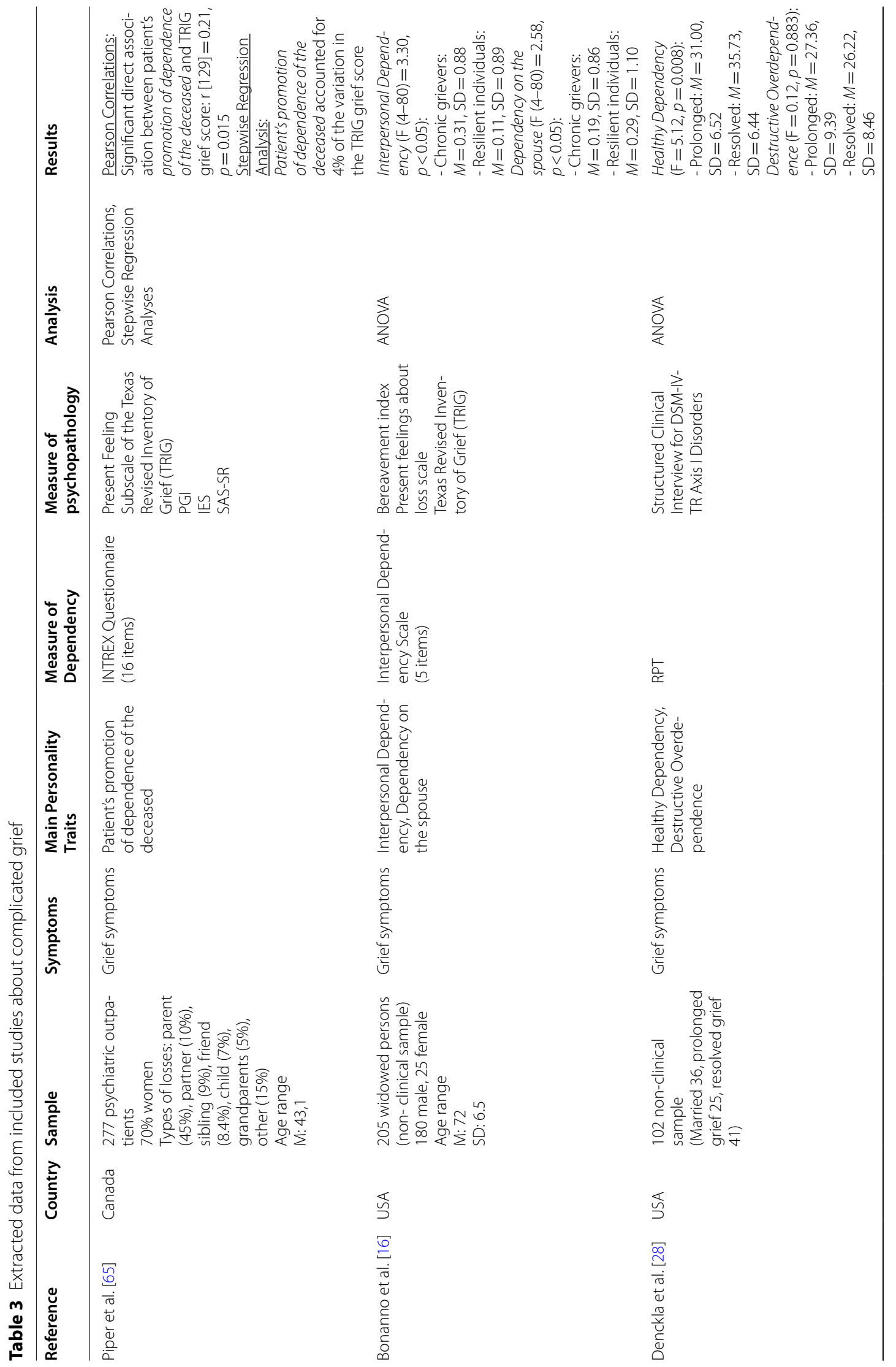




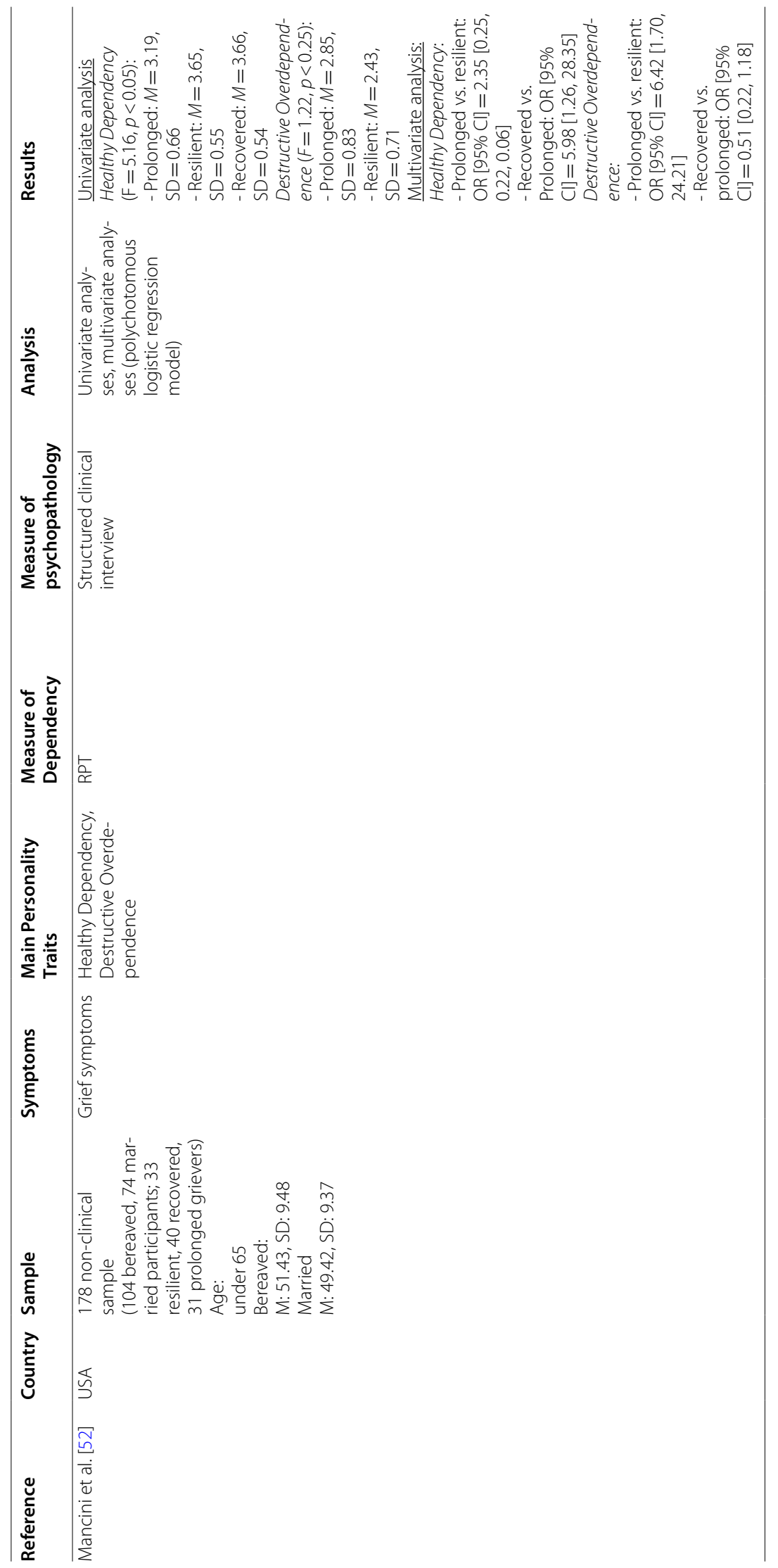




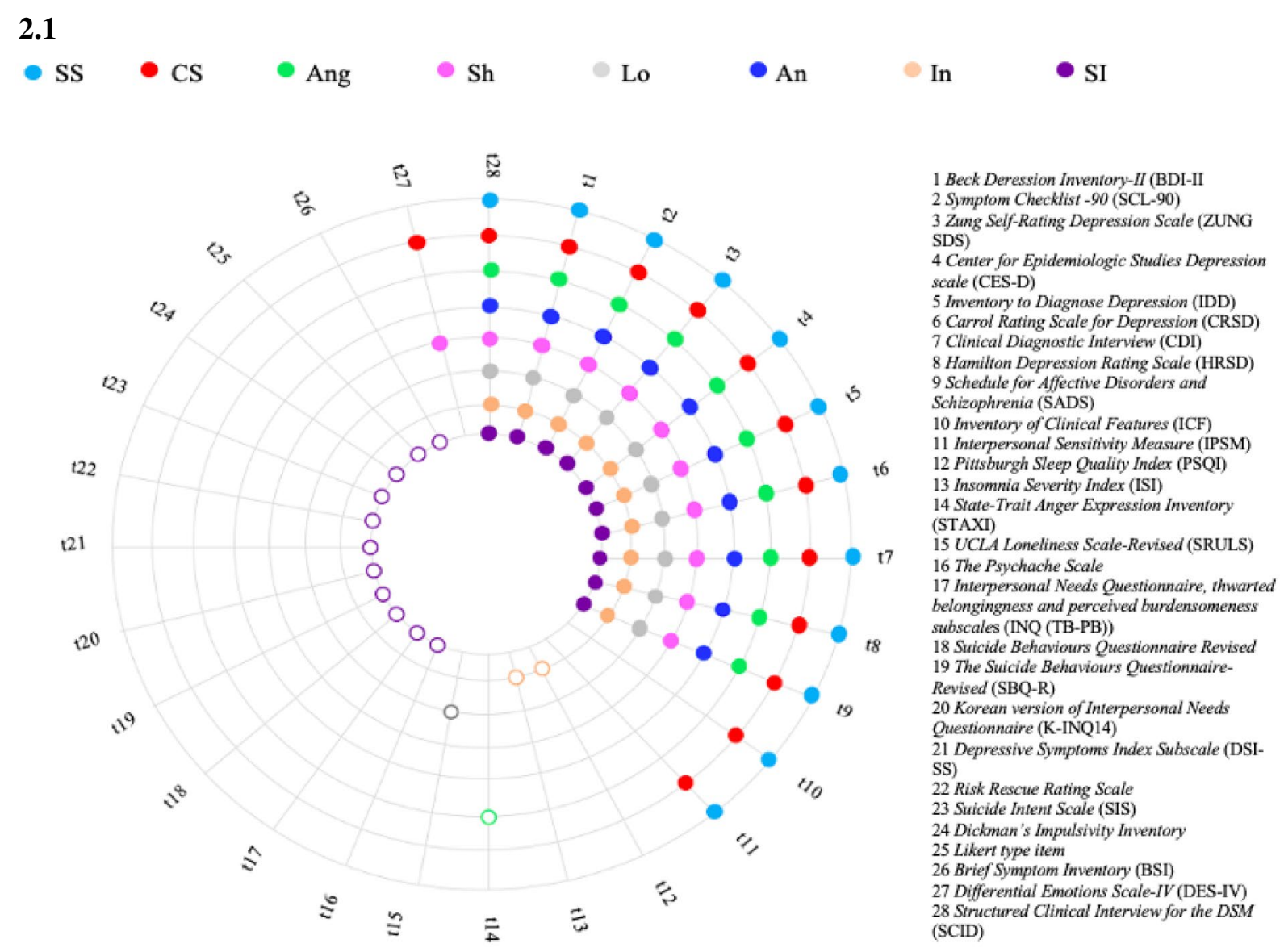

- Test measures a cluster of symptoms

Test measures only the symptom of interest

2.2

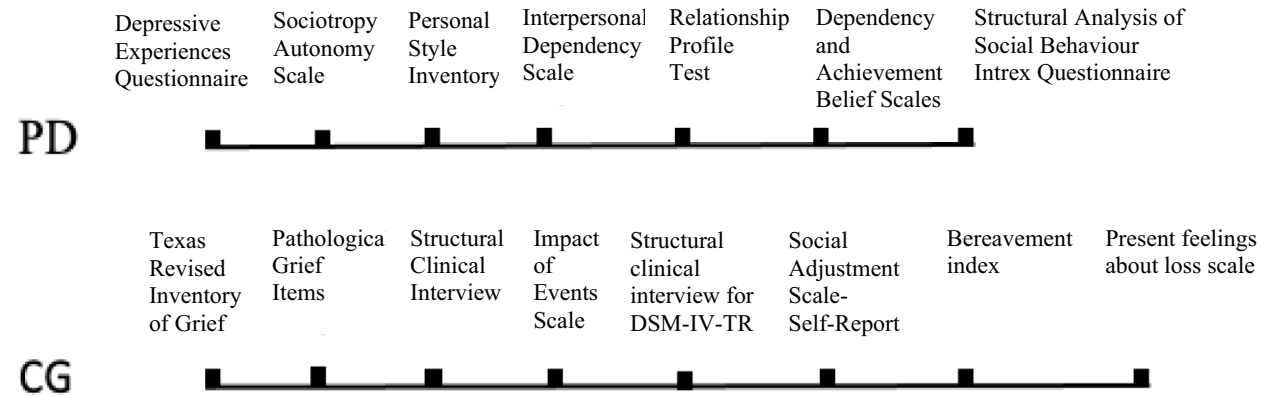

Fig. 2 Tests measuring depressive symptoms, complicated grief, and personality dimensions. 2. 1 SS (Somatic Symptoms): loss of pleasure, crying, agitation, loss of interest, loss of energy, changes in sleeping, irritability, changes in appetite, concentration difficulty, tiredness or fatigue, loss of interest in sex, interpersonal sensitivity. CG (Cognitive Symptoms): such as sadness, pessimism, past failure, guilty feelings, punishment feelings, self-dislike, self-criticalness, indecisiveness, worthlessness, self-blame, work difficulty, social withdrawal, hopelessness. Ang: Anger; Sh: Shame; Lo: Loneliness; An: Anhedonia; In: Insomnia; SI: Suicidal Ideation. Coloured circles indicate that the scale measures a cluster of symptoms. Empty circles indicate that the scale measures only the symptom of interest). 2.2 Tests measuring personality dimensions and complicated grief. PD (Personality dimensions); CG (complicated Grief) 
failure, work inhibition, sense of punishment, lack of satisfaction, self-hatred, social withdrawal (BDI), irritability, indecisiveness, personal devaluation (ZUNG-SDS), feeling blocked in getting things done, feeling easily annoyed or irritated and feeling of being caught or trapped (SCL90). Dependency doesn't show a strong relationship with the dependent composite in the Major Depressive Disorder sample (Hotelling's $t(90)=1.90$, ns). By contrast, self-criticism shows a strong relationship with the self-critical composite in the Major Depressive Disorder sample (Hotelling's t $(90)=-3.49$, Ps $<0.01$ ). To specifically examine the Interpersonal Sensitivity $(r=0.621$; $p<0.001$ ), Otani and colleagues [59] demonstrated a significant correlation between sociotropy and interpersonal sensitivity $(r=0.621 ; p<0.001)$ and its subscales, such as interpersonal awareness $(r=0.551 ; p<0.001)$, separation anxiety $(r=0.569 ; p<0.001)$, timidity $(r=0.513$; $p<0.001)$, and fragile inner self $(r=0.419 ; p<0.001)$; whereas only the fragile inner self subscale was significantly correlated $(r=0.193 ; p<0.001)$ with the autonomy subscale. Also, multiple regression analyses showed that sociotropy predicted total interpersonal sensitivity scores $(\beta=0.613 ; p<0.001)$, interpersonal awareness $(\beta=0.547$; $p<0.001)$, separation anxiety $(\beta=0.558 ; p<0.001)$, timidity $(\beta=0.518 ; p<0.001)$, fragile inner self $(\beta=0$. 0.398; $p<0.001)$, with autonomy predicting only fragile inner $\operatorname{self}(\beta=0.130 ; p<0.01)$.

\section{Other depressive symptoms (loneliness, self-conscious emotions, anhedonia, insomnia, anger)}

Seven studies $[1,4,11,19,32,74,76]$ examined potential differences between autonomic and sociotropic personality styles in levels of loneliness, shame, guilt, embarrassment, interpersonal intimacy, self-punitiveness, anhedonia, hopelessness, insomnia, and anger.

A positive and stronger association is reported between self-criticism and loneliness $(r=0.43, p<0.0001 ; r=0.62$, $P<0.0001$ for self-criticism for intimate and non-intimate relationship, respectively) [11]; $(r=0.67, p<0.01)$ [74] and a smaller association between dependency and loneliness $(r=0.22, p<0.05 ; r=0.13, p=0.22$ for intimate and non-intimate relationships, respectively) [11], $(r=0.34, p<0.01)$ [74]. Regression analysis also revealed that self-criticism has a stronger effect in predicting loneliness $(\beta=0.22, t=2.05, p<0.04$ and $\beta=0.46, t=4.28$, $p<0.0001$, in intimate and non-intimate relationships groups, respectively) [11], $(\beta=0.63, t=6.761, p<0.05)$ [74] compared to dependency $(\beta=0.04, t=0.43, p=0.18$ and $\beta=0.05, t=0.65, p=0.52$, in intimate and non-intimate relationships) [11], $(\beta=0.29, t=2.888, p<0.05)$ [74].

Regarding self-conscious emotions, introjective orientation appears to be significantly associated $(p \leq 0.01)$ with increased embarrassment $(\beta=0.281)$, shame $(\beta=0.381)$, guilt $(\beta=0.232)$, and it is also reported to predict $(p \leq 0.01)$ significantly reduced interpersonal intimacy $(\beta=-0.426)$. The self-criticism subcomponent was also related to self-punitive symptoms $(r=57)$ and hopelessness $(r=32)$ [19]. By contrast, anaclitic orientation appears to be significantly associated $(p \leq 0.01)$ only with embarrassment $(\beta=0.359)$ and guilt $(\beta=0.215)$ and it significantly predicts increased interpersonal intimacy $(\beta=0.266)$ [32], an association between dependency and self-punitive symptoms $(r=34$ has also been found [19]. An enhanced anhedonic symptomatology also emerged in introjective but not in anaclitic individuals compared to normal ones (normal vs. introjective $\Delta \mathrm{M}=-1.20, \mathrm{SE}=0.32, p<0.01$ Bonferroni) [76], in line with the association between anhedonia and only "pure" autonomy components $(r=30)$ [19]. Furthermore, in Bar and colleagues' study [4], they observed that self-criticism predicts insomnia only in individuals with quite high (2SDs above the mean depression symptoms $(\beta=0.06, \mathrm{SE}=0.03, p=0.04,95 \% \mathrm{CI}[0.00,0.12]$, and it is marginally significant for those with high (1SD above the mean depression symptoms $(\beta=0.03, \mathrm{SE}=0.02$, $p=0.07,95 \% \mathrm{CI}[-0.00,0.08]$, and not significant in those with mean $(\beta=0.01, \mathrm{SE}=0.01, p=0.40,95 \% \mathrm{CI}$ $[-0.02,0.05]$ and below mean (1SD below the mean levels of depression symptoms $(\beta=-0.00, \mathrm{SE}=0.02$, $p=0.68,95 \%$ CI $[-0.05,0.03]$. Finally, findings suggest that self-criticism is significantly associated $(p<0.01)$ with high levels of both state $(r=0.177)$ and trait anger $(r=0.393)$, low anger control $(r=-0.220)$, and high levels of anger towards the self $(r=0.455)$ and others $(r=0.319)$, whereas dependency appears to be related with high levels of trait anger $(r=0.060)$, the turning of anger towards the self $(r=0.119)$, and low levels of anger directed towards others $(r=-0.117)$ [1].

\section{Suicidality}

Six $[21,36,37,57,74,80]$ examined whether the personality dimensions of self-criticism and dependency are differently associated with suicidal behaviour and the subcategories related to it. Self-critical individuals are shown to have a higher tendency toward suicide than dependents [74]. Pearson $r$ correlations indicate a total correlation between autonomy and its subscales with suicidal ideation $(r(311)=0.16, p<0.01$. $[60,61]$, with people scoring higher on self-criticism also showing higher risk $(r=0.53)$, risk-rescue $(r=0.55)$, subjective lethality $(r=0.42)$, intent scores $(r=0.49)$, and lower rescue scores $(r=-0.50)$ compared to dependents $(r=-0.44)$, $(r=-0.55)$; $(r=-0.25)$; $(r=-0.24)$; $(r=0.58)$. Furthermore, standard multiple regressions showed that only self-criticism was a significant predictor of subjective 
lethality $(\beta=0.50)$ and of the intensity of a person's desire to die $(\beta=0.76)$ while dependency was not $(\beta=-1.57)$; $(\beta=-1.83)$ [36]. Another study found standardised discriminant function coefficients for self-criticism as a predictor of suicidal behaviour to be 0.46 (95\% CI $(0.13$, $0.66)$ ), suggesting its implication in suicidality and general psychological distress [21]. This result was also confirmed in another study [23], with a structural equation modelling or direct association model (SEM) demonstrating a significant association only between self-criticism and suicidality $(\beta=0.40, t=2.394, p<0.017)$, and a non-significant association between dependency and suicidality $(\beta=0.10, t=0.712$, ns). A $2 \times 2$ between subject multivariate analysis of variance (MANOVA) confirmed a difference between dependency and self-criticism on different lethality indices $(p=0.05)$, and a significant negative correlation was found between dependency and state impulsivity $(r=0.40, n=96, p<0.01)$, while a significant positive correlation was found between self-criticism and state impulsivity $(r=0.35, p<0.01)$ [37]. Moreover, a difference has been found between younger adult and older adult samples concerning the association between the autonomic personality trait and its subscales-Need for Control, Perfectionism and Defensive Separation-measured on the PSI-II [70] and suicidal behaviour [57]. In the younger adult sample, the total score on the autonomy scale $(r=0.27$ and each autonomy subscales of Need for Control $(r=0.16$, Perfectionism $(r=0.29$ and Defensive Separation $(r=0.23$ was significantly and positively associated with suicidality, while in the older adult sample, this association was only shown in Need for Control $(r=0.26$. Also, multiple linear regressions examining the association between propensity for suicidal behaviour and autonomy subscales have indicated only Defensive Separation $(\beta=0.11, S E=0.03, p<0.01,95 \% C I=0.05$, 0.16 ), and Perfectionism $(\beta=0.38, \mathrm{SE}=0.06, p<0.01,95 \%$ $\mathrm{CI}=0.25,0.50)$ as being significantly related to suicidality in the younger sample; as opposed to Need for Control $(\beta=-0.05, S E=0.04, p>0.05,95 \% \mathrm{CI}=-0.01,0.04)$. In contrast, in older people only Need for Control appears to be significantly and positively associated with propensity for suicidality $(\beta=0.21, S E=0.08, p<0.01,95 \%$ $\mathrm{CI}=0.05,0.37)$, while Defensive Separation $(\beta=-0.04$, $S E=0.06, p>0.013,95 \% \mathrm{CI}=-0.14,0.07)$ and Perfectionism $(\beta=-0.10, S E=0.14, p>0.013,95 \% \mathrm{CI}=-0.38$, $0.19)$ are not.

\section{Indirect effects and distress of suicidality}

In studies examining if the interaction between the independent variables of interpersonal needs-perceived burdensomeness (PB) and thwarted belongingness (TB) - and self-criticism and dependency predict suicidality or suicidal ideation dependent variables, regression analysis in a model including TB, PB, sociotropy and autonomy for moderation effects revealed TB not being a valid predictor of suicidal ideation, while $\mathrm{PB}(\beta=0.24$, $t(298)=0.42, p<0.001)$ and sociotropic personality $(\beta=-0.11, t(298)=-2.26, p<0.05)$ demonstrated significance in predicting current suicidal ideation. Other simple slope analyses have shown that sociotropic effects on suicidality were significant when the level of TB was high (i.e., one standard deviation above the mean), $t$ $(294)=-2.62, p=0.009$ ), while autonomy was a predictor of suicide when PB levels were either low (i.e., one standard deviation below the mean), $t(294)=-2.35$, $p=0.019$, or high (i.e., one standard deviation above the mean), $t(294)=2.56, p=0.011$, indicating autonomy to be the only risk factor for suicidality [60,61]. Also, with regard to indirect effects, in a design with threetime points, depression symptoms seem to mediate the relationship between self-criticism and TB. A structural equation modelling showed that Time 1 autonomy predicted Time 2 depression symptoms $(\beta=0.137$, $p=0.002)$, and Time 2 depression symptoms predicted Time $3 \mathrm{~PB}(\beta=0.251, p=0.002)$, as well as Time $3 \mathrm{~TB}$ $(\beta=0.283, p=0.005)$ [56]. However, dependency, or neediness, was also shown to be significantly related to suicidality $(\beta=0.21, t=4.71, p<0.001 ; \mathrm{SE}=0.028,95 \% \mathrm{CI}$ $[0.14,0.30], p<0.001)$ as well as self-criticism $(\beta=0.20$, $t=4.17, \quad p<0.001 ; \quad \mathrm{SE}=0.029, \quad 95 \%$ CI $[0.11,0.30]$, $p<0.001)$ and depression $(\beta=0.57, t=8.00, p<0.001$; $\mathrm{SE}=0.004,95 \%$ CI $[0.44,0.70], p<0.001)$ indirectly through the effect of psychache and interpersonal needs (TB, PB) [22].

Distress, in terms of independent variable, also seems to indirectly mediate the relationship between personalities of self-criticism, dependency and suicidality dependent variables, with a mediational structural equation modelling (SEM) including self-criticism, dependency, distress and suicidality revealing that the relationship between self-criticism and high levels of suicidal behaviours was mediated by high levels of distress $(\beta=0.54$, $t=6.452, p<0.0001)$, as well as high levels of dependency significantly associated with high levels of distress $(\beta=0.36, t=4.459, p<0.0001)$, and high levels of distress significantly associated with suicidality $(\beta=0.51$, $t=2.284, p<0.022$ ). Indirect association between high levels of self-criticism and high levels of suicidality $(z=2.18, p<0.03)$ and high levels of dependency and high levels of suicidality $(z=2.08, p<0.04)$ were also all found to be significant [23].

\section{Complicated grief}

Higher scores of interpersonal dependency and dependency on the spouse have been found in chronic grievers ID: $M=0.31, \mathrm{SD}=0.88, \mathrm{~F}(4-80)=3.30, p<0.05$; DOS: 
$M=0.19, \quad \mathrm{SD}=0.86, \quad \mathrm{~F} \quad(4-80)=2.58, \quad p<0.05) \quad$ compared to resilient individuals (ID: $M=0.11, \mathrm{SD}=0.89$, $\mathrm{F}(4-80)=3.30, p<0.05 ; \mathrm{DOS}: M=0.29, \mathrm{SD}=1.10, \mathrm{~F}$ $(4-80)=2.58, p<0.05)$ [16]. Lower levels of healthy dependency have been found in prolonged grievers compared to resolved grievers $\mathrm{MD}=-4.73, p=0.015$ ) [28], as well as lower levels of healthy dependency in prolonged grievers $(M=3.19, \mathrm{SD}=0.66, F=5.16, p<0.05)$ compared to resilient $(M=3.65, \mathrm{SD}=0.55, F=5.16, p<0.05)$ and recovered $(M=3.66, \mathrm{SD}=0.54, F=5.16, p<0.05)$ individuals, and higher levels of destructive overdependence in prolonged grievers $(M=2.85, \mathrm{SD}=0.83, F=1.22$, $p<0.25, \mathrm{DF}=2,62)$ compared to resilient individuals $(M=2.43, \mathrm{SD}=0.71, F=1.22, p<0.25)$, despite a little significance due to the small sample size [52]. A significant association between individual's promotion of dependency of the deceased and grief score $(r[129]=21$, $p=0.015)$ was also observed [65].

\section{Discussion}

This systematic review was conducted in order to test the Symptom Specificity Hypothesis according to which anaclitic-sociotropic and introjective-autonomic personality dimensions are related to specific depression symptoms. More specifically, in line with this hypothesis, we hypothesised that a dependent-sociotropic-anaclitic personality style would have been related to more somatic symptoms and complaints such as crying, tearfulness, shame, loneliness, anger, anxiety symptoms, anhedonia and a more masked depressive form; while self-critical-autonomic-introjective personality would have been associated with cognitive symptoms, including failure feelings, self-hate, guilt, hostility, loss of interest and suicidality. Data collected showed a high heterogeneity and contrasting results across studies that do not totally support the hypothesis. In fact, most of the studies found weaker associations between somatic symptoms and dependent personalities. By contrast, as we had assumed, the relationship between self-criticism and cognitive symptomatology was significantly higher, with self-criticism being significantly associated with worthlessness, self-dislike, self-criticalness, defeat and failure, irritability, guilty feelings, self-hate, loss of interest, concentration difficulty, tiredness, changes in appetite and concerns about the ability to function [30, 47, 51, 69, 79]. Furthermore, self-criticism-in contrast to Blatt's [12] view of the introjective configurations-seems to be able to predict poorer social functioning at follow-up [47], as well as both cognitive and somatic symptoms of depression [79]. Some studies, however, supported the symptoms specificity hypothesis, reporting a relationship between dependency and symptoms specifically associated with crying or tearfulness, loss and deprivation and helplessness [47], mood-variability, reactivity and loneliness [69], interpersonal awareness, separation anxiety, timidity, fragile inner self [59], and self-punitive symptoms [19].

Contrary to what we expected-according to the theoretical link between dependency and loneliness suggested by Blatt [12]-loneliness seems to be more closely related to the introjective personality than the anaclitic one, highlighting the interpersonal difficulties associated with the self-critical dimension $[11,55,74,90]$. Also, an enhanced anhedonic symptomatology has been found to specifically characterise introjective individuals but not anaclitic individuals compared to normal ones [76]. In particular, Burke and Haslam [19] reported a link between anhedonia and core autonomy, a component of autonomy that comprised self-direction and freedom from attachments, this finding may account for the association between autonomy and endogenous depression reported by Peselow and colleagues [64]. Furthermore, self-emotions such as embarrassment [32] and guilt [19, 32] were shown to be associated both with sociotropy and autonomy, while shame appears to be the only emotion related to the introjective personality, supporting the opinion that shame is a fundamental emotion in the introjective personality, resulting in reduced interpersonal intimacy in these individuals [32, 75]. Finally, selfcriticism also appears to be strongly associated with high levels of both state and trait anger, low anger control and high levels of anger towards the self and others, suggesting that introjective personality is characterised by hostile and irritable issues in depression [1]. The association between high levels of self-criticism and increased anger toward others could play an important role in explaining the associated vulnerability to depression. That is, the turning of anger towards others has been shown to lead to vicious interpersonal cycles characterised by increased feelings of frustration and anger in significant others, resulting in social exclusion and subsequent loneliness and depression $[1,11,50,74]$. On the other hand, the anaclitic personality has been found to be associated with elevated levels of trait anger, low levels of anger directed toward others, and directing anger towards the self, suggesting that dependency is most closely related to depression associated with inhibited anger [1]. In this sense, some studies showed that dependent individuals often seem to underreport feelings of anger $[1,34,73]$, indicating that they may fear that admitting anger towards others will lead to rejection and abandonment. Finally, the interaction between the introjective personality and depression symptoms has been found to predict insomnia, while no study identified the presence of sleep disorders in the anaclitic personality dimension. 
Several studies [36, 37, 57, 71, 80], also tried to apply the Symptoms Specificity Hypothesis on suicidal behaviour in order to investigate whether different suicidal paths and patterns can be observed between the two groups, showing both sociotropy and autonomy to be associated with different suicidal characteristics. In particular, self-critical individuals indicate a greater intent to die, higher lethality behaviours, and higher risk and risk-rescue scores along with lower rescue scores compared to patients scoring lower in the introjective-autonomic personality, while sociotropics seem to show higher rescue scores and lower suicidal risk, lower intent to die and risk-rescue if compared to those lower in dependency and to self-critical individuals. Lower rescue scores in self-criticism show the tendency of these individuals to adopt more precautionary behaviours against the possibility of being discovered during the suicidal act compared to dependents and use more active practices of suicide such as firearms [8], highlighting the greater risk of these individuals for suicidality. Dependent people otherwise utilise fewer precautions against being discovered, by adopting less lethal and more passive suicide methods and attempts such as overdose [37]. In summary, self-critics and dependents are reported to have a different vulnerability to attempting suicide, even depending on interpersonal or intrapsychic life events [36]: while sociotropics are more worried about dependent issues, autonomic individuals show more suicidal thoughts and their suicidal acts seem to be gestures rather than attempts, showing a greater risk for successful suicide [80]. More specific differences have been found between younger and older adults in relation to three introjective-autonomic personality subcomponents, where in younger adults, suicidality appears to be associated with autonomy's subscale of Perfectionism and Defensive Separation, in older adults only Need for Control autonomy's subscale was related to increased propensity for suicidal behaviour. Data suggest that the autonomy personality and its propensity to suicide can be different in relation to suicide risk, with age having a mediation role. For this reason, suicidal behaviour could also differ across the life span [26], with the Need for Control subcomponent seeming to reflect inflexibility, which in turn is associated with suicidality in old age [27]. According to the Interpersonal-Psychological Theory of Suicide [44], four studies [60, 61], focused on the possibility that sociotropy and autonomy could contribute to the development of two interpersonal dysfunctions$\mathrm{PB}$ and $\mathrm{TB}$ - that lead to suicide risk. Main results indicate an association between autonomy and $\mathrm{PB}$ and $\mathrm{TB}$ in predicting suicide, even with the mediation role of depression symptoms. Contrasting results, however, seem to show that sociotropy is also significantly related to suicidality through the indirect effect of $\mathrm{PB}$ and TB, and distress [23].

With regard to complicated grief, DSM-5 defines this clinical condition as a chronic grief experience that follows the loss of a loved one and is frequently associated with the expression of various somatic complaints such as digestive problems and pain and fatigue, resembling in some cases the masked form of depression typical of the anaclitic personality dimension. For this reason, we hypothesised that dependency was a risk factor and a predictor of complicated grief.

\section{Conclusions}

Overall, studies included in this review support the association between dependency and complicated grief, indirectly providing evidence of the hypothesised relationship between dependence and masked symptoms of depression. Nevertheless, it is important to note the limited number of studies examining the symptoms specificity hypothesis and their fragmented results, which in turn, leads to contrasting results in this review. This variability of results might be due to the fact that the selected studies do utilise different tests measuring anaclitic-sociotropic and introjectiveautonomic personality styles because relatively little attention has been focused only on the original DEQ and SAS according to Blatt's and Beck's theories (1874, 1983). Particularly, these tests assess different subcomponents of these personalities. Thus, it would be useful to create more unitary methodologies of evaluation, combining the components measured by all the tests included in this review. In addition, many studies examining depression symptoms are based on diagnostic criteria including mainly cognitive symptoms rather than other depressive forms, such as the somatic one.

Future directions should provide data from experimental and longitudinal research to specifically investigate the symptoms specificity hypothesis and, thus, to corroborate the hypothesised correlation between personality styles and specific clusters of depression symptoms. This might make an important contribution to the clinical context in terms of therapeutic implications, supporting the existence of a form of depression characterised by somatic features which should not be ignored by the main diagnostic criteria currently in use. This would improve the implementation of more effective and personalised treatments built on the single individual and on different symptoms among depressed patients. 


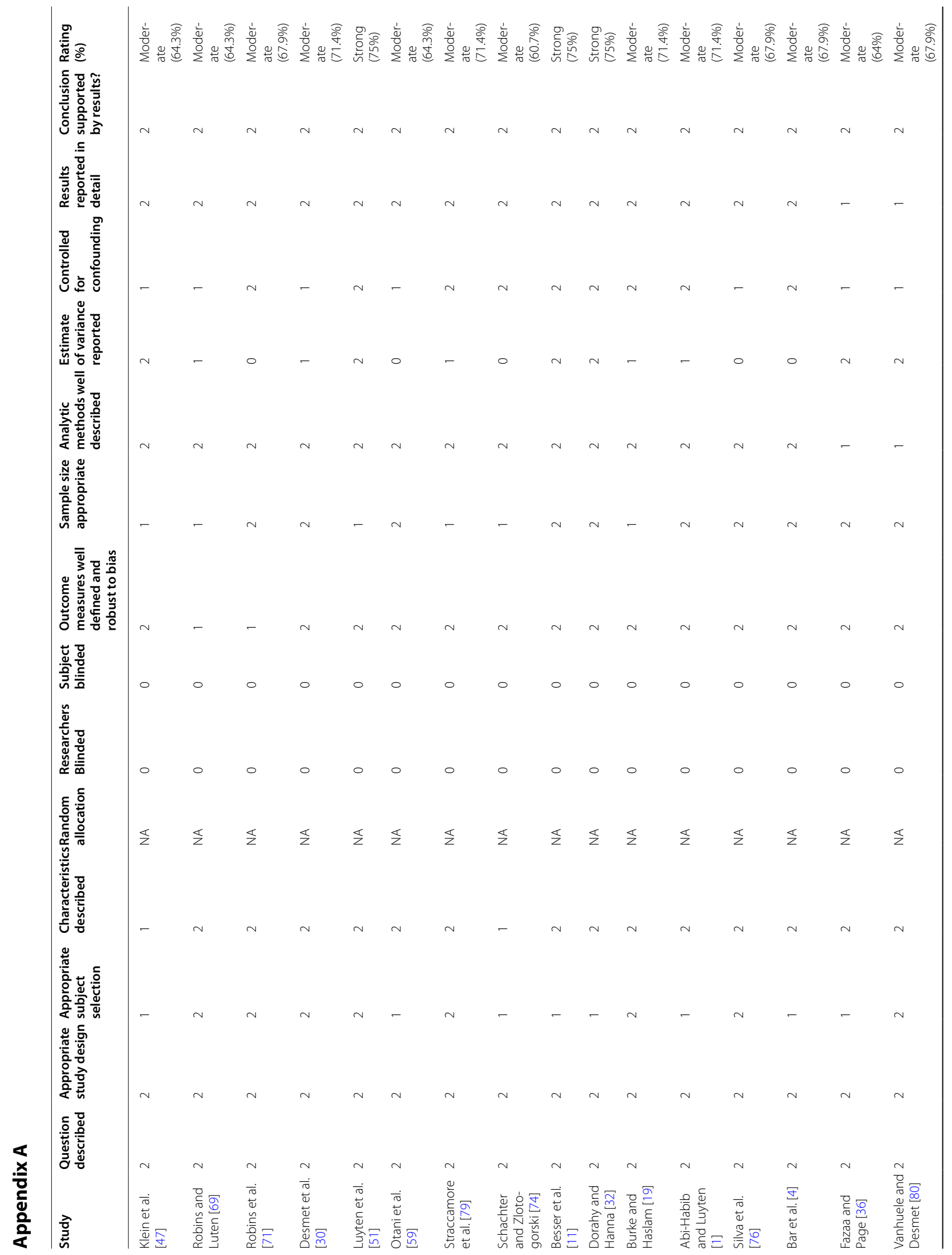


Marfoli et al. Annals of General Psychiatry ～(2021) 20:53

Page 27 of 30

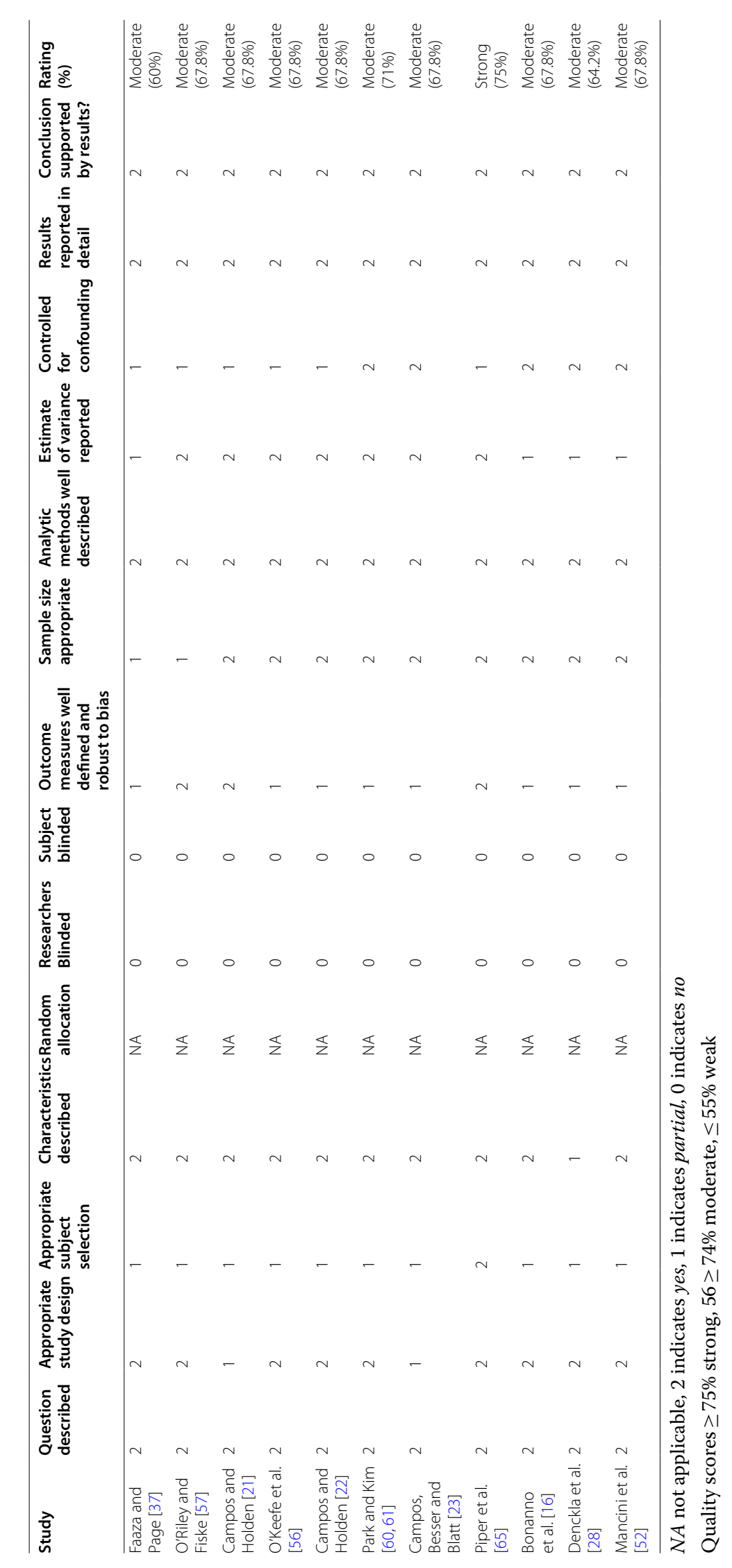




\section{Abbreviations}

An: Anhedonia; Ang: Anger; BDI-II: Beck Depression Inventory-Second Edition; BSI: Brief symptom inventory; CDI: Clinical diagnostic interview; CES-D: Center for Epidemiologic Studies Depression scale; CG: Cognitive symptoms; CRSD: Carroll rating scale for depression; DABS: Dependency and Achievement Belief Scales; DEQ: Depressive Experiences Questionnaire; DES-IV: Differential Emotions Scale; DSI-SS: Depressive Symptoms Index Subscale; DSM-IV-TR: Diagnostic and Statistical Manual of Mental Disorders, fourth edition, text revised; DSM-5: Diagnostic and Statistical Manual of Mental Disorders, fifth edition; HAMD: Hamilton Depression Rating Scale; ICF: Inventory of clinical features; IDD: Inventory to Diagnose Depression; IDS: Interpersonal dependency scale; IES: Impact of events scale; In: Insomnia; INQ (TB-PB): Interpersonal Needs Questionnaire, thwarted belongingness and perceived burdensomeness subscales; INTREX: Structural Analysis of Social Behaviour Intrex Questionnaire; IPSM: Interpersonal sensitivity measure; ISI: Insomnia severity index; K-INQ14: Korean version of Interpersonal Needs Questionnaire; Lo: Loneliness; MCMI: Millon clinical multiaxial inventory; MDD: Major depressive disorder; PGI: Pathological grief items; PRISMA: Preferred reporting items for systematic reviews and meta-analyses; PSI: Personal Style Inventory; PSQI: Pittsburgh Sleep Quality Index; PTSD: Post-traumatic stress disorder; RPT: Relationship Profile Test; SADS: Schedule for affective disorders and Schizophrenia; SAS-SR: Social Adjustment Scale-Self-Report; SAS: Sociotropy/Autonomy Scale; SBQ-R: The Suicide Behaviours Questionnaire-Revised; SCID: Structured Clinical Interview for the DSM; SCL-90: Symptom Checklist-90; Sh: Shame; SI: Suicidal ideation; SIS: Suicide Intent Scale; SS: Somatic symptoms; STAXI: State-Trait Anger Expression Inventory; SRULS: UCLA Loneliness Scale-Revised; TRIG: Texas Revised Inventory of Grief; ZUNG-SDS: Zung Self-Rating Depression Scale.

\section{Acknowledgements}

None.

\section{Disclosures}

The authors declare that they have no known competing financial interests or personal relationships that could have appeared to influence the work reported in this paper.

\section{Authors' contributions}

AC: conceptualization, supervision. MDC: writing — reviewing and editing. AM: conceptualization, methodology, writing —original draft preparation, data curation. SM: writing — reviewing and editing. SS: writing —reviewing and editing. FV: writing —original draft preparation, methodology, data curation. All authors have read and approved the final manuscript.

\section{Funding}

No financial support was provided.

\section{Availability of data and materials}

The authors can confirm that all relevant data are included in the article and/ or its Additional files.

\section{Declarations}

\section{Ethics approval and consent to participate}

Not applicable.

\section{Consent for publication}

Not applicable.

\section{Competing interests}

The authors declare that they have no competing interests.

Received: 3 August 2021 Accepted: 25 November 2021 Published online: 16 December 2021

\section{References}

1. Abi-Habib R, Luyten P. The role of dependency and self-criticism in the relationship between anger and depression. Personality Individ Differ. 2013;55(8):921-5.
2. American Psychiatric Association. Diagnostic and statistical manual of mental disorders (DSM-5). American Psychiatric Pub. 2013.

3. Arrindell WA, Ettema JHM. Klachtenlijst (SCL-90) [Dutch version of the Symptom Checklist-90]. 1986.

4. Bar M, Schrieber G, Gueron-Sela N, Shahar G, Tikotzky L. Role of selfcriticism, anxiety, and depressive symptoms in young adults' insomnia. Int J Cogn Ther. 2020;13(1):15-29.

5. Bastien $\mathrm{CH}$, Vallières $\mathrm{A}$, Morin $\mathrm{CM}$. Validation of the insomnia severity index as an outcome measure for insomnia research. Sleep Med. 2001;2(4):297-307.

6. Beck AT, Ward CH, Mendelson M, Mock J, Erbaugh J. An inventory for measuring depression. Arch Gen Psychiatry. 1961;4:561-71.

7. Beck AT, Kovacs M, Weissman A. Assessment of suicidal intention: the Scale for Suicide Ideation. J Consult Clin Psychol. 1979;47(2):343.

8. Beck AT. Cognitive therapy of depression: new perspectives. Treatment of depression: old controversies and new approaches. 1983.

9. Beck AT, Steer RA, Brown GK. Beck depression inventory (BDI-II) (Vol. 10, p. s15327752jpa6703_13). Pearson. 1996.

10. Benjamin LS. Short form Intrex users' manual. Salt Lake City: Intrex Interpersonal Institute, University of Utah; 1988.

11. Besser A, Flett GL, Davis RA. Self-criticism, dependency, silencing the self, and loneliness: a test of a mediational model. Pers Individ Differ. 2003;35(8):1735-52

12. Blatt SJ. Levels of object representation in anaclitic and introjective depression. Psychoanal Study Child. 1974;29:107-52.

13. Blatt SJ, D'Afflitti JP, Quinlan DM. Experiences of depression in normal young adults. J Abnorm Psychol. 1976;85(4):383.

14. Blatt SJ, D'Afflitti JP, Quinlan DP. Depressive experiences questionnaire. Yale University, school of medicine, Department of psychiatry. 1976.

15. Boyce P, Parker G. Development of a scale to measure interpersonal sensitivity. Aust NZ J Psychiatry. 1989;23(3):341-51.

16. Bonanno G, Lehman DR, Tweed RG, Haring M, Wortman CB, Sonnega J, Carr D, Nesse RM. Resilience to loss and chronic grief: a prospective study from preloss to 18-months postloss. J Pers Soc Psychol. 2002;83(5):1150-64.

17. Bornstein RF, Languirand MA, Geiselman KJ, Creighton JA, West MA, Gallagher HA, Eisenhart EA. Construct validity of the Relationship Profile Test: a self-report measure of dependency-detachment. J Pers Assess. 2003;80(1):64-74

18. Buysse DJ, Reynolds CF, MonkTH, Berman SR, Kupfer DJ. The Pittsburgh Sleep Quality Index: a new instrument for psychiatric practice and research. Psychiatry Res. 1989;28(2):193-213.

19. Burke A, Haslam N. Relations between personality and depressive symptoms: a multimeasure study of dependency, autonomy, and related constructs. J Clin Psychol. 2001;57(7):953-61.

20. Campbell DG, Felker BL, Liu CF, Yano EM, Kirchner JE, Chan D, et al. Prevalence of depression-PTSD comorbidity: implications for clinical practice guidelines and primary care-based interventions. J Gen Intern Med. 2007:22(6):711-8.

21. Campos RC, Holden RR. Suicide risk in a Portuguese non-clinical sample of adults. Eur J Psychiatry. 2014;28(4):230-41.

22. Campos RC, Holden RR. Testing a theory-based model of suicidality in a community sample. OMEGA J Death Dying. 2016;74(2):119-37.

23. Campos RC, Besser A, Blatt SJ. Distress mediates the association between personality predispositions and suicidality: a preliminary study in a Portuguese community sample. Arch Suicide Res. 2012;16(1):44-58.

24. Carroll BJ, Feinberg M, Smouse PE, Rawson SG, Greden JF. The Carroll rating scale for depression. I. Development, reliability and validation. $\mathrm{Br}$ J Psychiatry. 1981;138:194-200.

25. Clark DA, Steer RA, Haslam N, Beck AT, Brown GK. Personality vulnerability, psychiatric diagnoses, and symptoms: cluster analyses of the sociotropyautonomy subscales. Cogn Ther Res. 1997;21(3):267-83.

26. Conwell Y, Thompson C. Suicidal behavior in elders. Psychiatr Clin North Am. 2008:31(2):333-56

27. Conwell Y, Duberstein PR, Cox C, Herrmann JH, Forbes NT, Caine ED. Relationship of age and axis I diagnoses in victims of completed suicide: a psychological autopsy study. Am J Psychiatry. 1996. https://doi.org/10. 1176/ajp.153.8.1001.

28. Denckla CA, Mancini AD, Bornstein RF, Bonanno GA. Adaptive and maladaptive dependency in bereavement: distinguishing prolonged and resolved grief trajectories. Pers Individ Differ. 2011;51(8):1012-7. 
29. Derogatis LR. Brief symptom inventory. Johns Hopkins University. 1978.

30. Desmet M, Vanheule S, Verhaeghe P. Dependency, self-criticism, and the symptom specificity hypothesis in a depressed clinical sample. Soc Behav Personal Int J. 2006;34(8):1017-26.

31. Dickman SJ. Functional and dysfunctional impulsivity: personality and cognitive correlates. J Pers Soc Psychol. 1990;58(1):95.

32. Dorahy MJ, Hanna D. Shame, intimacy and self-definition: an assessment of the emotional foundation and intimate relationship consequences of an introjective personality orientation. J Nerv Ment Dis. 2012;200(8):699-704.

33. Endicott J, Spitzer RL. A diagnostic interview: the schedule for affective disorders and schizophrenia. Arch Gen Psychiatry. 1978;35(7):837-43.

34. Ewart CK, Jorgensen RS, Kolodner KB. Sociotropic cognition moderates blood pressure response to interpersonal stress in high-risk adolescent girls. Int J Psychophysiol. 1998;28(2):131-42.

35. Faschingbauer TR, Zisook S, DeVaul R. The Texas revised inventory of grief. Biopsychosocial aspects of bereavement. 1987. pp. 111-24.

36. Fazaa N, Page S. Dependency and self-criticism as predictors of suicidal behavior. Suicide Life Threat Behav. 2003;33(2):172-85.

37. Fazaa N, Page S. Personality style and impulsivity as determinants of suicidal subgroups. Arch Suicide Res. 2009;13(1):31-45.

38. First MB, Spitzer RL, Gibbon M, Williams JB. Structured clinical interview for DSM-IV-TR axis I disorders, research version, patient edition. New York, NY, USA:: SCID-I/P. 2002. pp. 94-1.

39. Goldberg D. The heterogeneity of "major depression."World Psychiatry. 2011;10(3):226

40. Hamilton M. A rating scale for depression. J Neurol Neurosurg Psychiatry. 1960;23:56-62.

41. Hirschfeld RM, Klerman GL, Gouch HG, Barrett J, Korchin SJ, Chodoff P. A measure of interpersonal dependency. J Pers Assess. 1977;41(6):610-8.

42. Holden RR, Mehta K, Cunningham EJ, McLeod LD. Development and preliminary validation of a scale of psychache. Can J Behav Sci. 2001;33:224-32.

43. Izard CE, Libero DZ, Putnam P, Haynes OM. Stability of emotion experiences and their relations to traits of personality. J Pers Soc Psychol. 1993;64(5):847-60.

44. Joiner TE. Why people die by suicide. Cambridge, MA, US: Harvard University Press; 2005

45. Kalamatianos A, Canellopoulos L. A diathesis-stress model conceptualization of depressive symptomatology. Psychiatriki. 2019. https://doi.org/10. 22365/jpsych.2019.301.49.

46. Keane TM, Kaloupek DG. Comorbid psychiatric disorders in PTSD: Implications for research. Ann NY Acad Sci. 1997;821(1):24-34.

47. Klein DN, Harding K, Taylor EB, Dickstein S. Dependency and self-criticism in depression: evaluation in a clinical population. J Abnorm Psychol. 1988:97(4):399.

48. Kmet LM, Lee RC, Cook LS. Standard quality assessment criteria for evaluating primary research papers from a variety of fields. Edmonton: Alberta Heritage Foundation for Medical Research 2004; 2014.

49. Likert R. A technique for the measurement of attitudes. New York: Archives of Psychology; 1932

50. Luyten P, Blatt SJ. Psychodynamic treatment of depression. Psychiatr Clin North Am. 2012:35(1):111-29.

51. Luyten P, Sabbe B, Blatt SJ, Meganck S, Jansen B, De Grave C, et al. Dependency and self-criticism: relationship with major depressive disorder, severity of depression, and clinical presentation. Depress Anxiety. 2007;24(8):586-96.

52. Mancini AD, Sinan B, Bonanno GA. Predictors of prolonged grief, resilience, and recovery among bereaved spouses. J Clin Psychol. 2015;71(12):1245-58

53. Mills TL. Comorbid depressive symptomatology: isolating the effects of chronic medical conditions on self-reported depressive symptoms among community-dwelling older adults. Soc Sci Med. 2001;53(5):569-78.

54. Moher D, Liberati A, Tetzlaff J, Altman DG. Preferred reporting items for systematic reviews and meta-analyses: the PRISMA statement. Int I Surg. 2010;8(5):336-41.

55. Mongrain M. Parental representations and support-seeking behaviours related to dependency and self-criticism. J Pers. 1998;66:151-73.

56. O'Keefe VM, Grant DM, Tucker RP, Lechner WV, Mills AC, Judah MR Wingate LR. Autonomy as a prospective predictor of perceived burdensomeness and thwarted belongingness through symptoms of depression. OMEGA J Death Dying. 2016;73(1):70-86.

57. O'Riley AA, Fiske A. Emphasis on autonomy and propensity for suicidal behavior in younger and older adults. Suicide Life Threat Behav. 2012:42(4):394-404.

58. Osman A, Bagge CL, Gutierrez PM, Konick LC, Kopper BA, Barrios FX. The Suicidal Behaviors Questionnaire-Revised (SBQ-R): validation with clinical and nonclinical samples. Assessment. 2001;8(4):443-54.

59. Otani K, Suzuki A, Kamata M, Matsumoto Y, Shibuya N, Sadahiro R. Interpersonal sensitivity is correlated with sociotropy but not with autonomy in healthy subjects. J Nerv Ment Dis. 2012;200(2):153-5.

60. Park Y, Kim HS. The interaction between personality and interpersonal needs in predicting suicide ideation. Psychiatry Res. 2019;272:290-5.

61. Park Y, Kim HS. Validation of the Korean version interpersonal needs questionnaire. Suicide Life Threat Behav. 2019;49(3):739-58.

62. Parkes CM, Weiss RS. Recovery from bereavement. New York: Basic Books Inc; 1983.

63. Persons JB, Burns DD, Perloff JM, Miranda J. Relationships between symptoms of depression and anxiety and dysfunctional beliefs about achievement and attachment. J Abnorm Psychol. 1993;102:518-24.

64. Peselow ED, Robins CJ, Sanfilipo MP, Block P, Fieve RR. Sociotropy and autonomy: relationship to antidepressant drug treatment response and endogenous-nonendogenous dichotomy. J Abnorm Psychol. 1992;99:393-7.

65. Piper WE, Ogrodniczuk JS, Joyce AS, Mccallum M, Weideman R, Azim HF. Ambivalence and other relationship predictors of grief in psychiatric outpatients. J Nerv Ment Dis. 2001;189(11):781-7.

66. Pompili M. Critical appraisal of major depression with suicidal ideation. Ann Gen Psychiatry. 2019;18(1):1-5.

67. Prigerson HG, Frank E, Kasl SV, Reynolds CF, Anderson B, Zubenko GS, et al. Complicated grief and bereavement-related depression as distinct disorders: preliminary empirical validation in elderly bereaved spouses. Am J Psychiatry. 1995;152(1):22-30.

68. Radloff LS. The CES-D scale: a self-report depression scale for research in the general population. Appl Psychol Meas. 1977;1(3):385-401.

69. Robins CJ, Luten AG. Sociotropy and autonomy: differential patterns of clinical presentation in unipolar depression. J Abnorm Psychol. 1991;100(1):74.

70. Robins CJ, Ladd J, Welkowitz J, Blaney PH, Diaz R, Kutcher G. The Personal Style Inventory: preliminary validation studies of new measures of sociotropy and autonomy. J Psychopathol Behav Assess. 1994;16(4):277-300.

71. Robins CJ, Bagby RM, Rector NA, Lynch TR, Kennedy SH. Sociotropy, autonomy, and patterns of symptoms in patients with major depression: a comparison of dimensional and categorical approaches. Cogn Ther Res. 1997;21(3):285-300

72. Russell D, Peplau LA, Cutrona CE. The Revised UCLA Loneliness Scale: concurrent and discriminant validity evidence. J Pers Soc Psychol. 1980:39:472-80.

73. Santor DA, Zuroff DC. Interpersonal responses to threats to status and interpersonal relatedness: effects of dependency and self-criticism. $\mathrm{Br}$ J Clin Psychol. 1997;36:521-41.

74. Scachter EP, Zlotogorski Z. Self-critical and dependent aspects of loneliness. Isr J Psychiatry Relat Sci. 1995;32(3):205-11.

75. Shahar G. Personality, shame and the breakdown of social bonds: the voice of quantitative depression research. Psychiatry. 2001;64:228-39.

76. Silva JR, Vivanco-Carlevari A, Martinez C, Krause M. Introjective individuals tend toward anhedonia: self-report and experimental evidence. Front Psych. 2018;9:298

77. Singh B, Raphael B. Postdisaster morbidity of the bereaved. A possible role for preventive psychiatry? J Nerv Ment Dis. 1981;169(4):203-12.

78. Spielberger CD. State-Trait anger expression inventory. Professional manual. Odessa: Psychological Assessment Resources Inc; 1996.

79. Straccamore F, Ruggi S, Lingiardi V, Zanardi R, Vecchi S, Oasi O. Personality factors and depressive configurations. An exploratory study in an Italian clinical sample. Front Psychol. 2017;8:251.

80. Vanheule S, Desmet M, Meganck R. Dependent and self-critical depression: evidence for subtypes? J Am Psychoanal Assoc. 2008;56(4):1352-7.

81. von Glischinski M, Teismann T, Prinz S, Gebauer JE, Hirschfeld G. Depressive symptom inventory suicidality subscale: optimal cut points for clinical and non-clinical samples. Clin Psychol Psychother. 2016;23(6):543-9. 
82. Van Orden KA, Cukrowicz KC, Witte TK, Joiner TE. Thwarted belongingness and perceived burdensomeness: construct validity and psychometric properties of the Interpersonal Needs Questionnaire. Psychol Assess. 2012;24(1):197-215.

83. Weiss DS, Marmar CR. The impact of event scale-revised. In: Wilson JP, Keane TM, editors. Assessing psychological trauma and PTSD. New York: Guilford; 1997.

84. Weisman AD, Worden JW. Risk-rescue rating in suicide assessment. Arch Gen Psychiatry. 1972;26(6):553-60

85. Weissman MM. Social adjustment scale-self-report. New York: MultiHealth Systems; 1999

86. Westen D. Clinical diagnostic interview. Emory University. Unpublished manual. 2004.

87. Zimmerman M, Coryell W. The Inventory to Diagnose Depression (IDD): self-report scale to diagnose major depressive disorder. J Consult Clin Psychol. 1987;55:55-9.
88. Zimmerman M, Ellison W, Young D, Chelminski I, Dalrymple K. How many different ways do patients meet the diagnostic criteria for major depressive disorder? Compr Psychiatry. 2015;56:29-34.

89. Zung WW. A self-rating depression scale. Arch Gen Psychiatry 1965;12(1):63-70.

90. Zuroff DC, Duncan N. Self-criticism and conflict resolution in romantic couples. Can J Behav Sci. 1999;31:137-49.

\section{Publisher's Note}

Springer Nature remains neutral with regard to jurisdictional claims in published maps and institutional affiliations.
Ready to submit your research? Choose BMC and benefit from:

- fast, convenient online submission

- thorough peer review by experienced researchers in your field

- rapid publication on acceptance

- support for research data, including large and complex data types

- gold Open Access which fosters wider collaboration and increased citations

- maximum visibility for your research: over 100M website views per year

At BMC, research is always in progress.

Learn more biomedcentral.com/submissions 